\title{
The roles of tumor-derived exosomes in altered differentiation, maturation and function of dendritic cells
}

\author{
Reza Hosseini ${ }^{1}$, Leila Asef-Kabiri ${ }^{2 \dagger}$, Hassan Yousefi ${ }^{3 \dagger}$, Hamzeh Sarvnaz ${ }^{4}$, Majid Salehi ${ }^{5}$, \\ Mohammad Esmaeil Akbari ${ }^{2^{*}}$ and Nahid Eskandari ${ }^{1^{*}}$
}

\begin{abstract}
Tumor-derived exosomes (TDEs) have been shown to impede anti-tumor immune responses via their immunosuppressive cargo. Since dendritic cells (DCs) are the key mediators of priming and maintenance of T cellmediated responses; thus it is logical that the exosomes released by tumor cells can exert a dominant influence on DCs biology. This paper intends to provide a mechanistic insight into the TDEs-mediated DCs abnormalities in the tumor context. More importantly, we discuss extensively how tumor exosomes induce subversion of DCs differentiation, maturation and function in separate sections. We also briefly describe the importance of TDEs at therapeutic level to help guide future treatment options, in particular DC-based vaccination strategy, and review advances in the design and discovery of exosome inhibitors. Understanding the exosomal content and the pathways by which TDEs are responsible for immune evasion may help to revise treatment rationales and devise novel therapeutic approaches to overcome the hurdles in cancer treatment.
\end{abstract}

Keywords: Exosome, Tumor, Dendritic cell, Immunity

\section{Introduction}

Exosomes are nano-sized (30-150 nm) extracellular vesicles released virtually by all types of cells and their content robustly mirrors that of the parental cells [1]. In particular, tumor cells were shown to actively secrete a large amount of exosomes to provide intercellular communication with surrounding as well as distant cells [1]. These extracellular vesicles contain several types of mRNAs, micro RNAs, functional surface proteins, enzymes and lipids, which enable them to exert local or systemic effects through direct interactions with the cell surface receptors or via transferring their contents into

\footnotetext{
* Correspondence: neskandari16@gmail.com; profmeakbari@gmail.com 'Leila Asef-Kabiri and Hassan Yousefi contributed equally to this work.

${ }^{2}$ Cancer Research Center, Shahid Beheshti University of Medical Sciences, Tehran, Iran

'Department of Immunology, School of Medicine, Isfahan University of Medical Sciences, Isfahan, Iran

Full list of author information is available at the end of the article
}

recipient cells through plasma membrane fusion, endocytosis, phagocytosis, micro pinocytosis, and lipid raftmediated internalization [2, 3]. Compelling evidence demonstrates that tumor-derived exosomes (TDEs) function in favor of tumor progression and crucially participate in nearly all aspects of cancer development, such as angiogenesis, proliferation, and metastasis [2].

In addition, TDEs also give an advantage to tumor outgrowth by negatively regulating anti-cancer immune responses [4]. Several studies have shown that TDEs could inhibit anti-tumor immunity either through internalization by the target cells or through receptorligand interactions $[5,6]$. In this regard, it has been acknowledged that TDEs harbor a plethora of membrane-bound proteins (Fas-L, PD-L1, etc.) that can directly inhibit the anti-tumor activity of effector CD8+ $\mathrm{T}$ cells and NK cells [7]. More importantly, on the other hand, exosomes released from tumor cells can also be 
taken up or interact with antigen presenting cells (APCs) and may indirectly induce antigen-specific tolerance [8]. Of particular note, TDEs especially target dendritic cells (DCs) which are the most important and effective APCs that orchestrate immune responses by priming naive $\mathrm{T}$ cells and providing subsequent signals required for the activity of effector $\mathrm{T}$ cells [8]. In this regard, it has been shown that TDEs largely inhibit the differentiation of DCs from bone marrow progenitors and monocytes, while strongly promote the development of tumor supportive cells, such as myeloid-derived suppressor cells (MDSCs) [9-11]. Tumor-derived exosomes were also shown to carry several bioactive molecules that can interfere with the maturation of DCs, thus demolishing their capability in inducing effective anti-tumor responses [12]. Moreover, others have shown that TDEs can alter the function of well-differentiated mature DCs. According to the published data, the interaction/uptake of TDEs by mature DCs renders them to an immunosuppressive phenotype, which thereby can improve tumor immune evasion [13, 14].

On the contrast, since TDEs contain a variety of tumor-associated antigens, there is a large degree of consensus that exosomes released by cancer cells can stimulate DCs to support potent anti-tumor immunity development [15]. However, growing evidence indicates that the dominant effect of TDEs is immunosuppression, rather than immunostimulation [16]. Taken together, TDEs seems to negatively affect DCs, as the key mediators of immune responses, to prevent the development of effective anti-tumor immunity. However, a literature review on the molecular mechanisms by which tumorderived exosomes interfere with the biology of DCs is still lacking. Therefore, in the present study, we provide the published evidence on how TDEs could impair the differentiation, maturation, and function of DCs. We then briefly discuss the lessons learned from TDEsmediated DCs abnormalities for the translation of research into practice, and review advances in the design and development of exosome inhibitors as potential adjunctive therapy for cancer.

\section{Tumor-derived exosomes alter differentiation of DCs}

Dendritic cells (DCs) are rare types of immune cells that differentiate from both myeloid and lymphoid progenitors in the bone marrow or derive from monocytic cells, and are largely localized in tissues [17]. Several subgroups of DCs have been identified, but plasmacytoid DCs (pDCs) and conventional DCs (cDCs) are the most common populations. Plasmacytoid DCs mainly produce type I interferons, however the latters are key Ag presenting cells (APCs) optimally initiate naive/resting $\mathrm{T}$ cell responses [18]. Because of their specialized characteristics, cDCs actively capture, internalize, and process the foreign pathogenic Ags and self-non-tumor or tumor-derived Ags and then present to $\mathrm{CD} 4+$ and $\mathrm{CD} 8+\mathrm{T}$ cells via the MHC-II and MHC-I molecules, respectively [18]. It is now evident that the abnormal differentiation of DCs is one of the main contributors of non-responsiveness to tumors $[19,20]$. The impaired differentiation of DCs in the tumor context has been highlighted with the dominant infiltration of myeloid-derived suppressor cells (MDSCs) and decreased number/accumulation of mature DCs in several malignancies including breast, lung, cervical, and colorectal tumors [21]. Additionally, clear evidence indicates that the defects of DCs in cancers are systemic rather than localized to the tumor sites [22]. These observations imply that the tumor-derived soluble factors might potentially play a major role in the defective differentiation of DCs in the tumor context [23]. Several factors derived from tumors as well as associated cells from the surrounding tumor microenvironment (TME) have been described to interfere with DCs differentiation. However, growing data have emphasized the role of tumor-derived exosomes (TDEs) in the loss of stimulatory APC activity and subsequently diminished antitumor immune responses in tumor-bearing hosts [11]. Here, we summarized the published data on the mechanisms by which TDEs could alter the differentiation of DCs in tumors.

Early studies have shown that the administration of TDEs considerably increases a population of undifferentiated myeloid progenitors [24]. Indeed, an increment of myeloid-derived suppressor cells (MDSCs) is the hallmark of defects in DCs differentiation [25]. Several lines of evidence have indicated that TDEs can corrupt myelopoiesis in the cancer by blocking the differentiation of myeloid precursors (including DCs precursors), which results in fewer DCs and an accumulation of myeloid cells with immunosuppressive function called MDSCs [21]. The molecular mechanisms that drive this process are not completely understood and various biomolecules are assumed to be involved in the TDEs-mediated accumulation of MDSCs. Previous studies have shown that prostanoids (i.e. PGE2) derived from cyclooxygenase-1 (COX-1) and COX-2 can inhibit the differentiation of both bone marrow- and monocyte-derived DCs [26, 27]. Tumor-derived exosomes have also been shown to carry functional COX-2 enzymes and its product, PGE2 [16, $28,29]$. It was demonstrated that the internalization of TDEs containing PGE2 and TGF- $\beta$ by bone marrow precursors impedes DCs differentiation and instead promotes the induction of MDSCs [30, 31]. However, targeting exosomal PGE2 and TGF- $\beta$ abolished the ability of TDEs to induce MDSCs and restored DCs differentiation, indicating their pivotal role in DCs 
abnormalities [30, 31]. Moreover, it was shown that COX-2 can be exported via TDEs into target cells, which may further increase PGE2 secretion in TME and promote tumor growth [28, 32]. Tumor-derived exosomes were also reported to induce MDSCs through STAT-3 dependent manner [33]. Multiple evidence shows that TDEs release considerable amounts of IL-6, a wellknown STAT-3 activator, which has widely been recognized to inhibit DCs differentiation from CD34+ bone marrow progenitors $[18,33,34]$. Additionally, IL-6 released from TDEs has also been found to promote proliferation and inhibit apoptosis of MDSCs [21, 30, 35]. Likewise, it was demonstrated that exosomes derived from TS/A murine mammary tumor cells target human monocytes and myeloid precursors of the bone marrow and block their differentiation into DCs, mainly via IL-6 and STAT3 pathways [11]. Tumor-derived exosomes were also shown to contain several other activating components of the STAT-3 pathway, including HSP70 and HSP72, which can induce the development of MDSCs $[36,37]$. Nevertheless, other intracellular pathways might also be involved in TDEs-mediated DCs abnormal differentiation. In this regard, it has been shown that melanoma-derived exosomes can inhibit the differentiation of DCs from bone marrow progenitors with wild- type MyD88; however, no inhibitory effect was observed in MyD88-deficient precursors, demonstrating that TDEs can exploit the MyD88 pathway for preventing DCs differentiation [38].

More recent data show that human leukocyte antigen $G$ (HLA-G) molecules are also expressed on TDEs and play a key role in inhibiting DCs differentiation [39]. HLA-G is a non-classical $\mathrm{MCH}-\mathrm{I}$ molecule that aberrantly expressed in a variety of human tumors and mediates suppression of $\mathrm{T}$ cells, NK cells and DCs through binding to inhibitory receptors [40, 41]. It has been found that cancer stem cell (CSC)-derived exosomes bearing HLA-G can inhibit monocyte-derived DCs differentiation [39]. However, blocking HLA-G with antibodies nullified the effects of CSC-derived exosomes on DCs differentiation suggesting that HLA-G carried by extracellular vesicles plays an immunomodulatory role [39] (Fig. 1). Additionally, tumor exosomes are assumed to inhibit the differentiation of DCs through metabolic reprogramming [18]. Of note, TDEs are widely enriched in glycolytic enzymes converting glucose into extracelullar ATP and lactate in the local tumor-microenvironment [42, 43]. The accumulation of lactic acid can restrain the differentiation of DCs, whereas promoting the expansion of myeloid-derived suppressor cells (MDSCs) [44, 45] (Fig. 1).

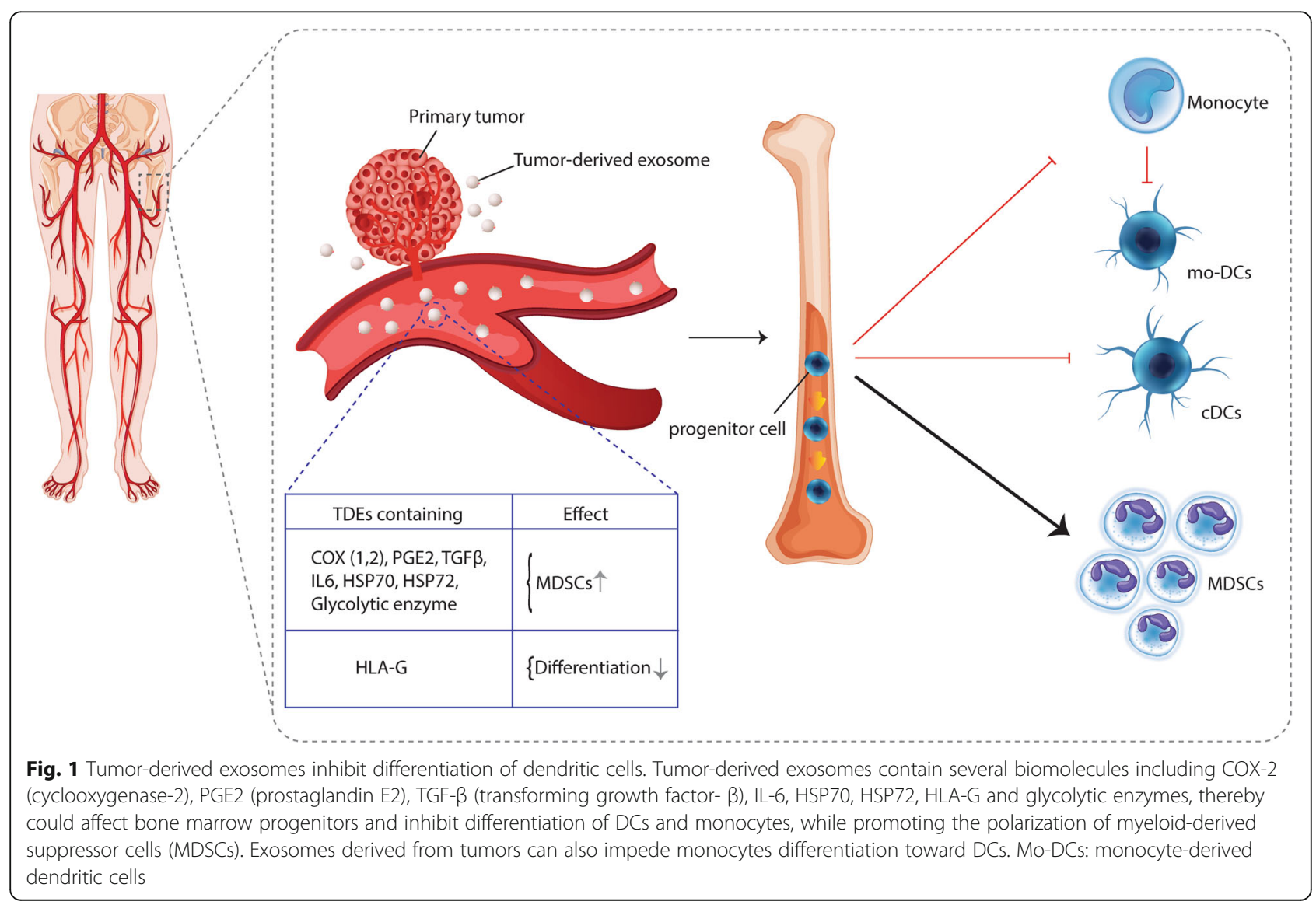




\section{Tumor-derived exosomes alter maturation of DCs}

Under the normal conditions, DCs are in an immature state expressing higher levels of phagocytic receptors, while characterized by low antigen-presenting capabilities [46]. Upon being induced by pathogen-associated molecular patterns (PAMPs) or damage-associated molecular patterns (DAMPs) through receptors such as CD40, TNF-R, IL-1R, and TLRs, DCs acquire a mature state expressing higher levels of antigen-loaded MHC-I and MHC-II molecules as well as costimulatory signaling B7 family molecules (e.g., CD80 and CD86) [46]. The presence of mature tumor-infiltrating DCs has been linked with the magnitude of anti-tumor $\mathrm{T}$ cell responses and a better prognosis in cancer patients [47]. However, in the context of tumors, DCs are mainly found in an immature phenotype unable to support normal levels of antigen-specific $\mathrm{T}$ cell expansion, leading to the induction of peripheral tolerance [48]. It is often unclear whether the immature phenotype of DCs reflects a simple failure of tumors to support the maturation and activation of these cells or, alternatively, active suppression of DCs maturation by tumors [26]. Up to now, several attempts have been made to resolve the intricacies dampening tumor-associated DCs maturation; but the limiting number of DCs that can be isolated from tumor-bearing animals and cancer patients and the complex nature of the cells and soluble factors present within the TME have made it difficult to gain mechanistic insights into the tumor-associated-impaired DC maturation in vivo [26]. In this regard, monocytic- and bone marrow-derived DCs (BMDCs) have been employed as suitable alternative ex vivo models to study the defective maturation of DCs by tumor cells or tumor-derived soluble factors [49]. The most recent studies, summarized in the following section, suggest that TDEs harboring several immunosuppressive biomolecules actively participate in the impaired maturation of DCs $[12,50]$.

As a pivotal mechanism, DCs actively phagocyte tumor cells that have undergone immunogenic cell death, then process their antigens and present to $\mathrm{T}$ cells (priming their activation), but environmental sensing and phagocytosis, to some extent, are inhibited in tumors. For instance, it has been shown that the alarmin high mobility group protein B1 (HMGB1) recruits nucleic acids from dead tumor cells into DCs endosomes, leading to the innate sensing of tumors [51]. However, the T-cell immunoglobulin and mucin-domain containing-3 (TIM-3) highly expressed on tumor-infiltrating dendritic cells (TIDCs) interacts with the nuclear protein HMGB1 and suppresses nucleic acids sensing-mediated stimulation of DCs [51]. Tumors were also shown to secrete higher amount of exosome-bound TIM-3 and Galectin-9 (ligand for TIM-3) which can be bound to TIM3 receptors on the TIDC and interfere with the antigen recognition, while may also induce a cascade of inhibitory signals [52]. Based on a research, exosomes isolated from NSCL $\mathrm{C}$ patients have exhibited higher content of Galectin-9 compared to the exosomes from healthy control donors [52]. Likewise, the exosomes isolated from the cerebrospinal fluid (CSF) of the patients with glioblastoma multiforme (GBM) have also been shown to contain higher amounts of Galectin-9 [53]. It was demonstrated that the Galectin-9 on the surface of GBM-CSF-derived exosomes can interact with the TIM3 receptor on dendritic cells (DCs) in the CSF to inhibit antigen recognition, processing and presentation by these cells, resulting in the failure of the cytotoxic T-cell-mediated antitumor immune responses [53]. Therefore, tumor-derived exosomal Galectin-9 acts as a major regulator of tumor progression by inhibiting DCs maturation and antigen presentation to activate cytotoxic T-cells in the CSF and that loss of this inhibitory effect can lead to durable systemic antitumor immunity [53]. As mentioned, TDEs also harbor TIM-3, but it is not clear whether the exosomal TIM-3 can bound HMGB1 and interfere with nucleic acid sensing of DCs or not (Fig. 2).

The CD47 a "don't eat me" signal, is another factor widely expressed by tumors which inhibits the sensing of mitochondrial DNA released by cancer cells via interaction with signal-regulatory protein- $\alpha$ (SIRP $\alpha)$ on DCs $[18,54]$. By engaging SIRP $\alpha$, CD47 limits the ability of DCs and macrophages to engulf tumor cells, which acts as a major phagocytic barrier [55]. The CD47 was also detected on the surface of exosomes released by tumors and the mouse mammary carcinoma-induced MDSCs, and was correlated with the enhanced retention of exosomes in the circulation $[56,57]$. It has been suggested that the CD47 expression can protect TDEs from phagocytosis by monocytes and macrophages [58]. This was proven, since CD47 deprived exosomes exhibited significantly less retention, suggesting that CD47 presence on exosomes limits their clearance by circulating SIRP $\alpha+$ CD11+ monocytes [59]. It seems that by expressing CD47, TDEs may avoid to be taken up by DCs, but still can efficiently deliver their pro-tumorigenic contents. Exosomal CD47 has also been proven to facilitate MDSCs chemotaxis and migration, and accumulation of MDSCs in TME can further impair DCs maturation [60-62]. In light of these findings, TDEs harboring CD47 are assumed to play crucial roles in the tumor escape from immune cells (Fig. 2).

Others have also shown that TDEs enriched in S100A9 molecules are also capable of inhibiting DCs maturation [63]. A recent study revealed that exosomes isolated from afferent lymphatic fluid in patients with primary cutaneous melanoma have higher levels of S100A9 [63]. Immunohistochemistry and immunogold electron microscopy results confirmed the trafficking of 


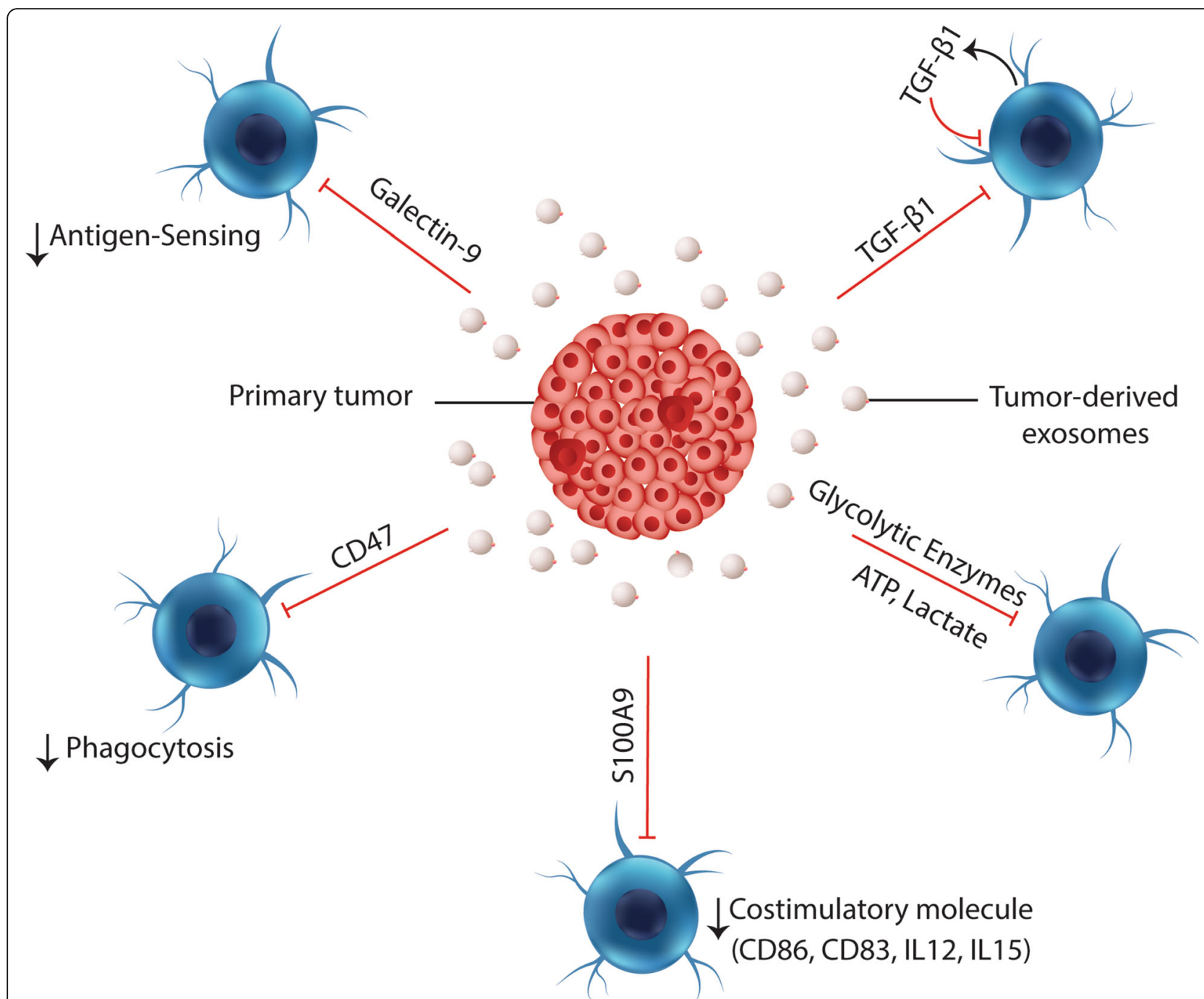

Fig. 2 Tumor-derived exosomes inhibit maturation of dendritic cells. Exosomal galectin-9 can interact with its cognate TIM-3 receptors on DCs and inhibit antigen-sensing by them. The expression of CD47 on TDEs inhibits their phagocytosis by immune cells and improves their retention in the circulation. Exosomal S100A9 downmodulates the maturation of DCs and decrease the expression of co-stimulatory CD83, CD86, IL-12 and IL-15 by DCs. Tumor exosomes induce DCs to express TGF- $\beta$, which further increases TGF- $\beta$ expression in an autocrine loop, and robustly inhibits anti-tumor immunity. Higher levels of glycolytic enzymes detected on TDEs can impair DCs maturation by increasing ATP and lactate levels In TME

tumor-derived S100A9 containing exosomes along the lymphatic path [63]. It was observed that the accumulation of S100A9 positive exosomes in the first node draining from the primary tumor, sentinel lymph node (SLN), is closely associated with a dysfunctional immune profile including reduced expression of dendritic cell maturation markers [63]. Importantly, this phenotype was observed prior to evidence of nodal metastasis [63]. These findings led to the conclusion that TDEs cargo, such as S100A9, may serve as early mediator of tumorinduced immune subversion in regional lymph nodes, establishing the niche for metastatic outgrowth. Likewise, others have also suggested that melanoma-derived extracellular vesicles (EVs) may participate in the premetastatic niche formation through cargo-specific polarization of DCs [50]. Accordingly, it was found that DCs matured in vitro in the presence of melanoma EVs had significantly impaired expression of CD83 and CD86 as well as decreased expression of Th1 polarizing chemokines Flt3L and IL15, and migration chemokines MIP- $1 \alpha$ and MIP- $1 \beta$ compared to liposome-treated DCs [50]. Profiling of melanoma EV cargo revealed shared proteomic and RNA signatures including S100A8 and S100A9 protein cargo [50]. Further experiments showed that similar to melanoma EVs-treated DCs, the incubation of DCs with S100A8 and S100A9 proteins compromised their maturation in vitro. These findings suggest a role for S100A8 and S100A9 molecules in TDEsmediated DCs abnormalities. These are in agreement with the earlier studies indicating that the higher level of 
S100A9 in the TME is, in part, responsible for the tumor-associated dendritic cells (TADCs)-mediated chemoresistance of breast cancer [64]. There is also other evidence indicating the importance of exosomal S100A9 in the altered maturation of DCs. In this regard, it has been demonstrated that paclitaxel can restore the maturation of DCs by decreasing the production of S100A9 and TNF- $\alpha$ by MDSCs, as the major source of the soluble/exosomal S100A9 in TME [65, 66]. In addition, exosomes enriched in S100A9 were also isolated from G-MDSCs and CLL patients, and were shown to induce the stemness of colorectal cancer cells by activating the $N F-\kappa B$ pathway [67]. All these findings indicate that tumor exosomes containing S100A8 and S100A9 proteins suppresses DCs maturation and improves the premetastatic niche formation in tumor-draining lymph nodes (Fig. 2).

In addition, previous studies have shown that treatment with tumor exosomes can induce TGF-b1 production in DCs [9, 34, 68-72]. Interestingly, this phenotype was associated with decreased expression of MHC class II and CD86 molecules, suggesting that TDEs inhibit the maturation of DCs [9]. TGF-b1 is known to inhibit the activation of lymphocytes and DCs, while converting effector $\mathrm{T}$ cells into Treg cells [73]. Moreover, exosomal TGF- $\beta$ has also been proven to be essential for the cancer cell migration [74].

Along with their effect on DCs differentiation, glycolytic metabolites in the TME can also impact their maturation. Previously, several studies have shown that tumor-derived lactate renders human monocytes into less mature DCs that are deficient in IL-12 secretion and are not able to effectively stimulate $\mathrm{T}$ cells $[23,44]$. As mentioned earlier, glycolytic enzymes have been identified in TDEs in substantial levels, which primarily convert extracellular glucose into ATP [42]. This was clearly mirrored by the tumor interstitial levels of ATP, which was demonstrated to be about 1000 times higher than those of normal tissues [75]. Since the presence of lactate dehydrogenase that catalyzes the conversion of pyruvate to lactate has been evidenced in TDEs, thus it is assumed that TDEs contribute to increased levels of lactate in the TME [43]. Eventually, these high levels of lactate can restrain DCs maturation while promoting the expansion of myeloid-derived suppressor cells (MDSCs), which are critically important for tumor progression [45]. There are several other studies have also confirmed that exosome-mediated metabolic reprogramming plays a crucial role in the intercellular communication between cancer cells and tumor associated cells. In this regard, it has been identified that tumor-associated macrophages (TAMs)-derived exosomes transfer HISLA to breast cancer cells, to prevent HIF-1a degradation, thus promoting aerobic glycolysis [76]. Instead, tumor cells release lactate that increases the expression of HIF$1 \alpha$-stabilizing long noncoding RNA (HISLA) in TAMs [76]. All these findings highlight the importance of TDEs in metabolic reprogramming of TME, contributing to immune escape and tumor progression (Fig. 2).

\section{Tumor-derived exosomes alter DCs function}

In addition to subverting DCs biology by altering differentiation (inducing toward MDSCs) and maturation (preventing acquisition of mature DCs features), tumors also interfere with the function (antigen-presenting capability) of fully matured DCs [77]. Notably, in early-stage tumors, DCs represent an immature phenotype which can induce paramount $\mathrm{T}$ cell proliferation ex vivo after being pulsed with tumor lysates, however at advanced stages, DCs are not simply immature and exhibit a semimature phenotype with compromised antigen-presenting activities [78, 79]. Indeed, DCs in advanced tumors exhibit a lower but still significant expression of MHC-II and costimulatory $\mathrm{CD} 40$; however, they also coexpress higher levels of co-inhibitory molecules (e.g. B7-H1) and exhibit increased arginase I and IDO activity comparable to that seen in MDSCs [21, 77]. Such DCs, called regulatory DCs, can result in either $\mathrm{T}$ cell anergy (unresponsiveness at the time of priming) or exhaustion (insufficient responses due to exposure to the negative costimulation), hence actively contribute to tumor growth through the inhibition of protective anti-cancer immunity [21]. How tumors induce immunosuppressive DCs has not clearly been identified, but there are multiple factors in TME that can transform conventional DCs with antigen-presenting capabilities into immunosuppressive players. Recent evidence indicates a significant role for tumor-derived exosomes (TDE) in altering the function of tumor-associated DCs [16]. Here, we reviewed the literature to gather findings on the importance of TDEs in impairing the function of DCs in the tumor context.

As mentioned, the lesser expression of MHC molecules on DCs in tumor bearing hosts has been assumed to considerably responsible for their compromised function. A recent study profiled the immune cells of the patients with pancreatic cancer has revealed substantial phenotypic changes in various immune cell populations, especially an increased population of immunosuppressive monocytes (CD14 + HLA-DRlo/neg) [31, 80, 81]. Further in vitro assessments demonstrated that the interactions between pancreatic TDEs and monocytes are responsible for HLA-DR downregulation in these cells [80]. Based on the observations, treatment of monocytes with TDEs can alter the STAT3 signaling pathway, which results in HLA-DR downregulation and upregulation of immunosuppressive arginase- 1 expression and reactive oxygen species production $[31,80]$. 
In another study, it was found that GBM-derived extracellular vesicles do not directly inhibit $\mathrm{T}$ cell activation [82]. Rather than, these tumor-derived EVs induce immunosuppressive monocytes, thereby inhibit the activation of anti-tumor $\mathrm{T}$ cells [82]. The expression of PDL1 on tumor-derived EV has been suggested to induce this inhibitory phenotype in monocytes [82]. Since tumor-associated DCs highly express PD-1, therefore PD-L1 expressing TDEs may negatively affect their function via PD-L1/PD-1 axis [83-85]. Likewise, several other studies have also shown that the exosomal PD-L1 can directly skew the function of immune cells toward tumor-promoting phenotype [86]. In another study, it was found that treatment of DCs with TDEs significantly inhibited the maturation and migration of DCs [12]. These TDEs-treated DCs drastically decreased CD4+ IFN- $\gamma+$ Th1 differentiation but increased the rates of regulatory $\mathrm{T}$ (Tregs) cells. Further experiments revealed that the immunosuppressive ability of tumor exosometreated DCs was partially restored with PD-L1 blockade [12]. The most recent studies indicate that exosomal PDL1 plays a vital role in tumor immune escape as well as in tumor resistant to anti-PD-1/PD-L1 immunotherapy [12]
(Fig. 3). Besides of its expression on TDEs, it has also been shown that TDEs can induce PD-L1 expression on monocytes, the precursor to DCs and macrophages [87, 88]. In this regard, exosomes from glioblastoma (GBM)-derived stem cells (GSCs) were shown to traverse the monocyte cytoplasm, causing a reorganization of the actin cytoskeleton, and skew monocytes toward the immunosuppressive M2 phenotype, including programmed death-ligand 1 (PD-L1) expression [87]. Mass spectrometry analysis demonstrated that the GDEs contain a variety of components, including members of the signal transducer and activator of transcription 3 (STAT3) pathways that functionally mediate this immunosuppressive switch [87]. Western blot analysis revealed that upregulation of PD-L1 in GSC exosome-treated monocytes and GBM-patient-infiltrating CD14+ cells predominantly correlates with increased phosphorylation of STAT3 [87]. Others have shown that the paired expression of PD-1; PD-L1 on DCs is correlated with the tumor progression, loss of positive costimulatory markers (CD80, CD86, and CD40), a lack of cytokine release (IL-12, IL-10, IL-6, TNF $\alpha$, and G-CSF), and contactdependent inhibition of $\mathrm{T}$ cell expansion [78, 89]. Cumulatively, these data indicate that TDEs are potent

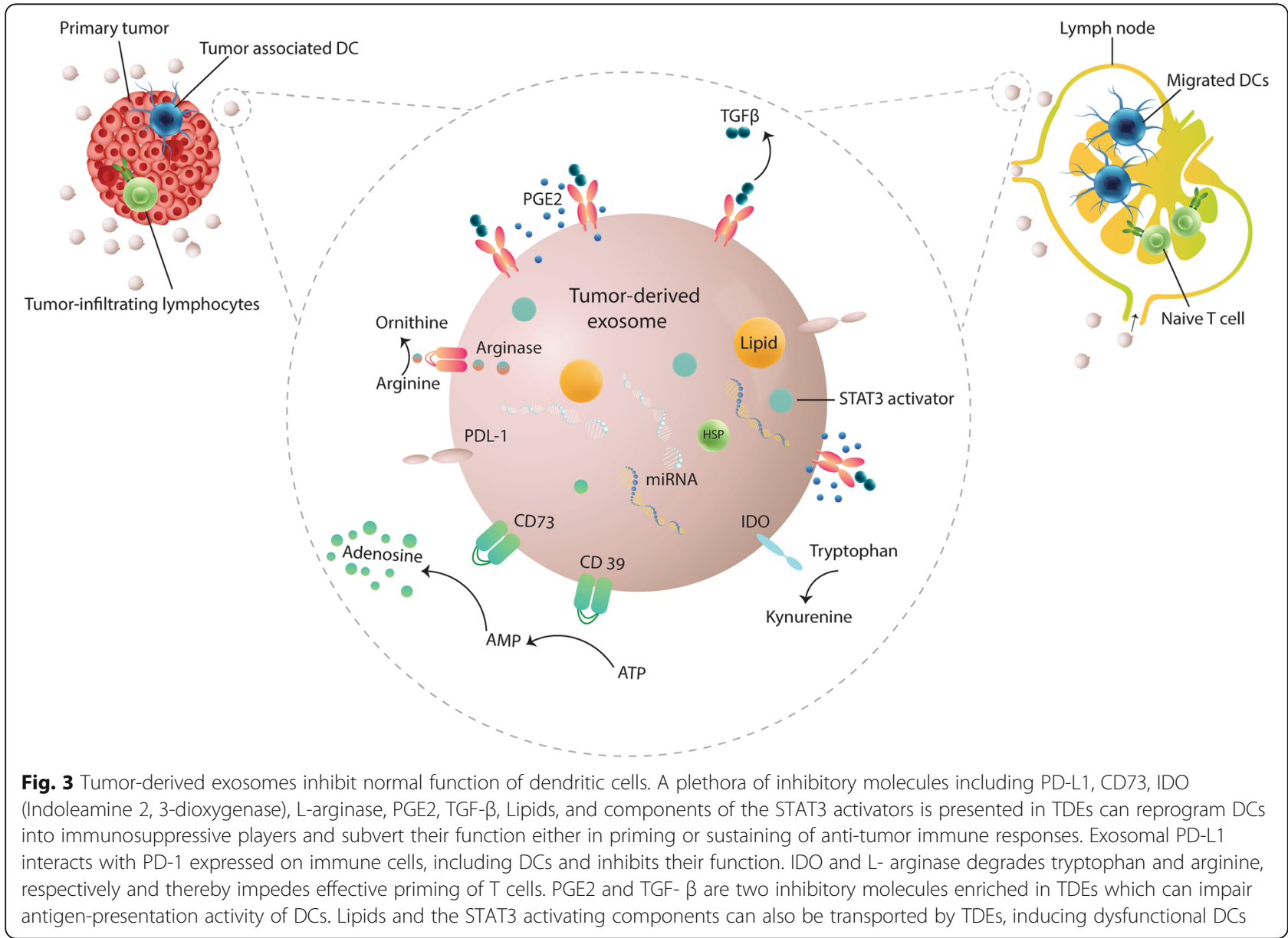


modulators of the tumor-associated immunosuppressive microenvironment and play a significant role in DCs functional abnormalities (Fig. 3).

Tumor-derived exosomes may also contribute to DCs dysfunction through indoleamine-pyrrole 2, 3-dioxygenase (IDO) pathway [90-92]. In a previous study, DCs cultured with IDO+ exosomes derived from BMSCs had downregulated CD40, CD86, CD80, MHC-II, but the increased secretion of anti-inflammatory cytokines compared with the other groups [93]. It has been shown that tumor/exosomal IDO produces kynurenine by degrading tryptophan, which in turn can induce IDO activity in DCs by interacting with the aryl hydrocarbon receptor (AHR) $[94,95]$. This is in line with the previous studies indicating that tumorassociated immunosuppressive DCs are the major source of IDO within the tumor-microenvironment promoting malignant progression [96]. Additionally, functionally compromised DCs can also release IDO+ exosomes, which may further enhance immunosuppression [97]. Therefore, tumor exosomes carrying IDO can contribute to DCs dysfunction by producing kynurenine as well as inducing the expression of IDO on DCs (Fig. 3). In addition, arginase-1 (ARG1), another key enzyme driving immunosuppression, was also detected in exosomes from several cancers [98-100]. Recently, it has been found that exosomes isolated from the ascites and plasma of ovarian cancer patients contain ARG1 [99]. The findings demonstrated that ARG1-containing exosomes are transported to draining lymph nodes and taken up by dendritic cells, leading to the inhibition of antigen-specific T-cell proliferation. It is well known that the upregulation of ARG1 activity in TME results in a reduced availability of arginine [101]. Previous studies clearly show that drops in the extracellular arginine levels can induce DCs dysfunction via downregulating the MHC-II molecules [102, 103]. Tumor exosomes and arginine restriction might also induce ARG1 expression on DCs, further enhancing immunosuppression [24, 99]. This is in agreement with the previous reports showing that DCs isolated from advanced tumors exhibit significant L-arginase activity [79]. Besides, exosomal ARG1 can also directly inhibit immune responses, since arginine is essentially needed for the activity of effector T cells [99].

It has been shown that PGE2 and TGF- $\beta$, both present in TDEs, are also critically involved in the abrogated function of tumor-associated DCs via the upregulation of ARG1 activity, IDO, and co-inhibitory molecule $\mathrm{B} 7-\mathrm{H} 1$ and $\mathrm{B} 7-\mathrm{DC}$, as well as the IL-10 production [33, 104]. In addition, exosomal PGE2 and TGF- $\beta$ were clearly demonstrated to inhibit DCs function through the induction of tolerogenic mediators, two ecto-enzymes CD39 and CD73, that act sequentially to generate anti-inflammatory extracellular adenosine [16]. In a recent study, it was found that exosomes derived from prostate cancer cells contain PGE2 which can induce CD73 expression on DCs and suppress their function [16]. CD73 was proven to pair with CD39 that is consistently expressed on DCs, and converts extracellular ATP into adenosine. The subsequent engagement of adenosine with the adenosine A2A receptor (A2AR), expressed on DCs and effectors $\mathrm{T}$ cells, could robustly play against anti-tumor immunity [105] (Fig. 3).

Other tumor-microenvironment components can also impair tumor-associated antigen presentation capability of DCs. For instance, the higher levels of lipid peroxidation can increase endoplasmic reticulum stress of DCs in tumor-microenvironment, which in turn impair the function DCs by increasing lipid accumulation [106]. Indeed, it has been shown that DCs with a higher load of lipids have the defective ability in processing and crosspresentation of exogenous antigens [106, 107]. Moreover, the intracellular lipid accumulation can inhibit the effective trafficking of MHC-I-peptide complexes to the cell surface [106, 108]. Recently, it has been identified that TDEs contribute to DCs dysfunction by transferring fatty acids [109]. Based on the evidence, delivering fatty acids by TDEs could induce the expression of peroxisome proliferator-activated receptor (PPAR) in DCs, which in turn increase both the biogenesis and oxidation of fatty acids [109]. The excess amount of intracellular lipid droplets/ fatty acid oxidation-by products can result in dysfunctional DCs via increased mitochondrial oxidative phosphorylation [109]. Therefore, based on these findings, TDEs can induce metabolic reprogramming in DCs either by transferring or inducing the production of lipids (Table 1 and Fig. 3).

\section{Lessons learned from TDEs-mediated DCs dysfunction}

In spite of containing a variety of immunosuppressive biomolecules, TDEs are also rich in tumor antigens and could provoke anti-tumor immunity [110]. Previously, it has been demonstrated that DCs could uptake TDEs, process their antigens and present to CD4 and CD8 positive $\mathrm{T}$ cells via $\mathrm{MHCII}$ and $\mathrm{MHCI}$, respectively, inducing antigen-specific CTL responses [110]. These findings inspired numerous studies to investigate the potential utility of TDEs (isolated from patients' plasma or tumor cell cultures) as tumor antigen sources in DCbased vaccination for cancer prevention and treatment $[15,110,111]$. There is now a great deal of evidence that shows greater anti-tumor activity for TDEs-pulsed DCs in comparison to tumor lysate-loaded DCs, giving rise to a consensus that DCs loaded with TDEs could serve as a novel promising approach for tumor immunotherapy [112]. However, the immunoinhibitory content of TDEs that causes DCs to become dysfunctional, as discussed in this review, has largely been overlooked in TDEs- 
Table 1 The content of tumor-derived exosomes (TDEs) and their effects on developmental stages of DCs

\begin{tabular}{|c|c|c|}
\hline Exosome content & Mechanism of Action & Ref \\
\hline \multicolumn{3}{|l|}{ Inhibition of DCs Differentiation } \\
\hline $\begin{array}{l}\text { Cox-2, PGE2, TGF-b1, IL-6, HSP-70, } \\
\text { and HSP-72 }\end{array}$ & $\begin{array}{l}\text { Promoting the polarization of myeloid-derived suppressor cells (MDSCs), mainly through } \\
\text { the STAT-3 pathway }\end{array}$ & $\begin{array}{l}{[24-29,31-33,} \\
35-38]\end{array}$ \\
\hline Glycolytic Enzymes & Increasing ATP and lactic acid levels and enhancing MDSCs population & {$[18,42-45]$} \\
\hline HLA-G & Blocking monocyte-derived DCs differentiation & [39] \\
\hline \multicolumn{3}{|l|}{ Inhibition of DCs Maturation } \\
\hline Galectin-9 and TIM-3 & Interacting with TIM-3 on DCs and reducing nucleic acid sensing & [51-53] \\
\hline CD-47 & Reducing phagocytosis by interacting with SIRP-a on DCs & [54-60] \\
\hline S100A9 & Downregulating CD83, CD86, IL-12 and IL-15 expression levels & {$[63-67]$} \\
\hline TGF-b1 & Induction of TGF-b1 secretion by DCs & {$[9,68,73,74]$} \\
\hline Lactate dehydrogenase & Increasing ATP and lactate levels in tumor microenvironment & {$[43-45,75,76]$} \\
\hline \multicolumn{3}{|l|}{ Inhibition of DCs Function } \\
\hline STAT3 activators & Reducing the levels of MHC and CD83 and CD86 molecules & {$[31,34,80]$} \\
\hline PD-L1 & Inducing PD-1 expression and transferring of negative signals & {$[12,82-88]$} \\
\hline IDO & $\begin{array}{l}\text { - Decreasing the levels of CD40, CD83, CD86 and MHC molecules } \\
\text { - Degrading tryptophan into kynurenine } \\
\text { - Kynurenine-meditated increase of IDO expression on DCs }\end{array}$ & {$[93,95-97]$} \\
\hline L-arginase (ARG1) & $\begin{array}{l}\text {-Impedes the DCs-mediated T cells priming in regional lymph nodes } \\
\text { - Reduces arginine level in tumor microenvironment, resulting in lower expression of } \\
\text { MHC molecules }\end{array}$ & {$[24,98-100]$} \\
\hline PGE and TGF-b1 & $\begin{array}{l}\text { Increasing CD73 expression on DCs, resulting in increased levels of inhibitory adenosine } \\
\text { in tumor site }\end{array}$ & {$[16,24,104,105]$} \\
\hline Lipids & Accumulating lipids in DCs, interfering with their antigen-presentation function & [106-109] \\
\hline
\end{tabular}

loaded DC vaccine strategies [14]. It might be expected that immunosuppressive cargo of TDEs would affect the therapeutic potential of TDEs-loaded DCs. This idea is supported by the findings showing that the engineered exosomes lacking inhibitory molecules can induce more effective anti-tumor responses in DC-based vaccine design $[113,114]$. For instance, it has been demonstrated that DCs loaded with TGF-b1-depleted exosomes induce greater anti-tumor CTLs compared to DCs pulsed with TGF-b1-expressing exosomes [113, 115]. In another study, it was also found that treatment of DCs with TDEs loaded with interleukin 12 (IL-12) or deprived of TGF-b1 could strongly support induction of anti-tumor immune responses compared to unmodified TDEs [116]. This shows that engineering exosomes to carry a customized cargo can be helpful in maximizing the therapeutic benefits of TDEs-loaded DC vaccines and should be carefully considered in future studies [114].

Furthermore, since tumors constantly release exosomes into the surrounding environment as well as into the circulation, these virus-sized vesicles are very likely to also interfere with the immune therapies in vivo, including DC vaccines $[117,118]$. This becomes more evident, as the immunosuppressive cargo of TDEs has been evidenced to abolish the efficacy of adaptive NK92 cell therapy in acute myeloid leukemia patients [117].
Circulating TDEs have also been proved to interfere with the therapeutic effects of monoclonal anti-HER2, -CD20 and -PD-1/PD-L1 antibodies [119-123]. Moreover, tumor exosomes have widely been reported to mediate resistance to common chemotherapies [86, 117, 124126]. However, strikingly, targeting exosomal inhibitory biomolecules or blockade of exosome release from cancer cells could strongly induce anti-tumor immunity and improve the anti-cancer effects of chemotherapeutic agents $[118,120,127-130]$. These data suggest that a strategy for targeting circulating tumor exosomes could add to the benefits of chemo- and immunotherapeutic interventions, possibly including DC-based therapies [118] (Fig. 4).

\section{Advances in targetting tumor-derived exosomes}

Due to the pivotal role that TDEs play in multiple aspects of tumor development and growth, such as proliferation, angiogenesis, metastatic niche formation and immune escape, a strong interest has emerged in recent years to selectively inhibit the generation/release of tumor exosomes as an adjunctive therapy for cancer [120, 127, 128]. The early research on exosome formation showed that these particles are highly enriched in sphingolipid ceramide and their release is significantly reduced in the presence of GW4869, a 


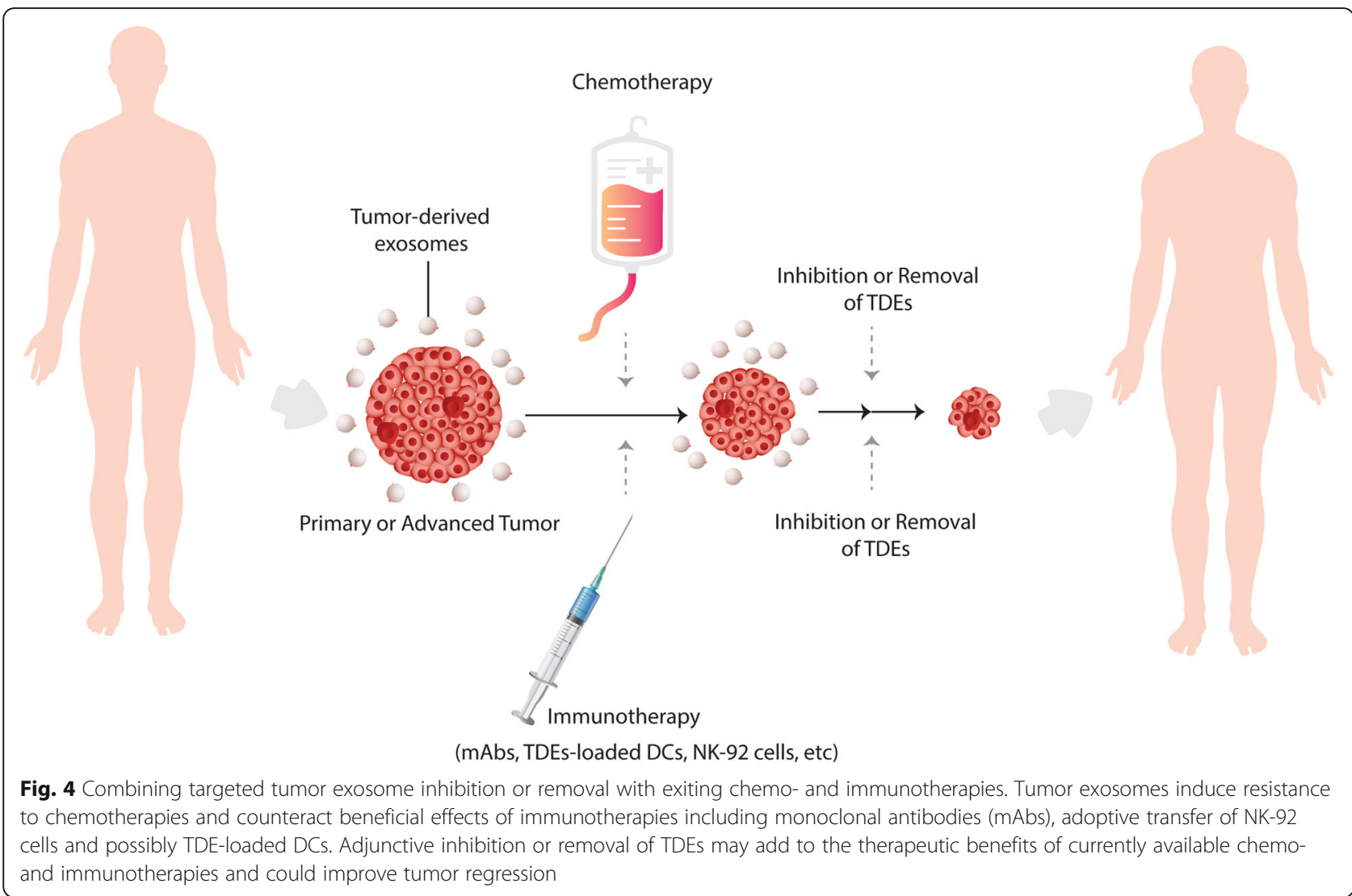

small molecule that inhibits neutral sphingomyelinase2 (nSMase2) [131, 132]. Further studies demonstrated that in addition to nSMase, ras-related $\mathrm{RAB}$ proteins are also important players of exosome biogenesis and knocking-down of RAB27A and RAB27B could significantly inhibit exosome shedding [133-135]. These findings provided preliminary insights into the underlying mechanisms of exosomes generation and unveiled potential targets for inhibiting their release. Over the past decade, tremendous efforts have been devoted to explore compounds capable of inhibiting nSMase and RAB27A expression as a possible route to block exosome secretion [135]. As a result, manumycin A [136], spiroepoxide [137, 138], cambinol [139], scyphostatin [140, 141], and DPTIP [142] were found to decrease exosome production by downregulating nSMase expression. More recently, researchers have used a high-throughput screening (HTS) technique to identify currently exited compounds with drug repositioning potential for exosome inhibition [143]. A total number of 4580 pharmacologically active compounds from the LOPAC library and the NPC library were examined and only tipifarnib, neticonazole, climbazole, ketoconazole, nexinhib20, nexinhib4, were found as potent exosome inhibitors [143]. Among these compounds, it has been demonstrated that nexinhib20 and nexinhib4, inhibitors of neutrophil exocytosis, can suppress exosome biogenesis by selective inhibition of RAB27A [144], however, tipifarnib, neticonazole, climbazole, and ketoconazole were shown to decrease exosome secretion by inhibiting RAB27A, Alix and nSMase2 [143]. Of note, the therapeutic value of tipifarnib in the adjuvant setting is under investigation in several clinical trials, and ketoconazole has currently been approved for the treatment of prostate cancer patients by the US Food and Drug Administration (FDA) [145-148]. Several other currently available drugs have also been identified with potential exosome inhibiting effects. Sulphisoxazole [149], ketotifen [150], cannabidiol $[151,152]$, pantoprazole [153, 154], esomeprazole [154], and imipramine [155] have been reported to exert potent blocking effects on exosome production with anti-cancer activity. Others have shown that chloramidine [155], bisindolylmaleimide-I [155], and the vitamin B5 derivative pantethine [156] can also inhibit the secretion of tumor exosomes. Dasitinib, a dual BCR/ABL and Src family tyrosine kinase inhibitor, was shown to prevent exosome release while promoting apoptosis in K562R (IMT) cells [157]. Recently, a synthetic peptide derived from the secretion modification region (SMR) of HIV-1 Nef, which 
carried PEG on the N-terminus and a Clusterin (Clu)-binding peptide on the C-terminus, was reported to inhibit metastasis and angiogenesis by causing a decrease in exosome release [158]. WEB2086, an antagonist of platelet-activating factor receptor (PAFR), was also proven to inhibit exosome release [159]. Dimethyl amiloride, a drug used to treat high blood pressure, has also been reported to inhibit exosome formation [36]. Additionally, anti-CD9 and anti CD63 antibodies as well as a hemofiltration device known as the Aethlon ADAPT ${ }^{\mathrm{TM}}$ (adaptive dialysis-like affinity platform technology) were shown to be useful in removing exosomes from circulation [130, 160].

By advances in our understanding of the basic biology of exosome formation and release, a number of new targets have also been identified. It has been shown that the gene silencing of tumor susceptibility gene 101 (TSG101), a member of Vps protein family which involves in exosome trafficking, inhibits exosome production in colon cancer cells [161]. Annexin A1 (ANXA1) has also been documented to play an important role in inward vesiculation and its suppression was associated with reduced exosome secretion in pancreatic cancer cells [162]. The proline-rich Akt substrate of $40 \mathrm{kDa}$ (PRAS40) has also been reported to regulate exosome secretion in breast and lung cancer cells [163]. Others have shown that the blocking of protease-activated receptor (PAR)-2, which binds to the tissue factor/factor VIIa, suppresses the secretion of TF-positive exosomes from pancreatic cancer cells [164].

\section{Future perspectives and concluding remarks}

The literature reviewed in this paper indicates that TDEs impair differentiation, maturation and function of DCs to favor immune escape and tumor outgrowth. Although several well-defined, proven mechanisms underlying the inhibitory effects of tumor exosomes on DCs biology were discussed in this review, but TDEs may also alter DCs behavior by a number of speculative mechanisms. For example, blockade of DCs differentiation has primarily been attributed to the presence of tumor-derived vascular endothelial growth factor (VEGF), and its levels were negatively correlated with the number of DCs in the circulation and TME in human cancers [18, 20, 21, 26, 165-172]. Tumor-derived exosomes were also shown to induce the release of VEGF by transferring miRNA21 into recipient cells, thus leading to increased VEGF levels within the tumor [173-175]. More recent findings also show that TDEs harbor an active isoform of VEGF, which is associated with the tumor outgrowth and resistance to common monoclonal antibody (mAb) therapies [176]. Besides, tumor cells also secrete excessive amounts of the gangliosides GD2 and GM3 that inhibit the differentiation of DCs from $\mathrm{CD}^{+} 4^{+}$as well as monocytic precursors, and induce apoptosis of monocyte-derived DCs [177-179]. These sialic acidcontaining glycosphingolipids were also shown to be shed from tumors via exosomes and can actively suppress immune cells $[26,180]$. Therefore, it can be postulated that several other exosomal biomolecules, including but not limited to VEGF, miRNA-21 and gangliosides, might play a role in the impaired differentiation of DCs in tumor context; however, their role has yet to be investigated. In addition, tumor exosomes were also reported to contain notable amounts of IL-10 [33, $74,81,181,182]$. The high levels of IL-10 were shown to inhibit DCs maturation by downmodulating the expression of MHC-I and costimulatory molecules, blocking the initiation of $\mathrm{T}$ cell responses [7, 21, 183, 184]. However, there is no evidence thus far that IL-10 plays a role in TDEs-mediated DCs defects. Future studies can shed light on the link between the above-mentioned exosomal markers and DCs abnormalities in cancer. Additionally, since different subpopulations of DCs exhibit distinct phenotypic characteristics and functional potential, thus it will be very important in future research to focus more attention on the effects of TDEs on DCs subgroups. Also, as discussed later in this review, great efforts have been made so far to target exosomes or exosomal markers to inhibit tumor progression and improve anti-tumor immunity. However, regardless of significant progress has been made in recent years in the discovery of exosomes inhibitors; it is still in its infancy and the therapeutic value of those inhibitors as adjunctive therapy for cancer has not yet been fully validated. Most of the compounds tested for exosome inhibition were highly cytotoxic and did not show selectivity to inhibit tumor exosomes, and thus may disrupt intercellular communication by inhibiting exosome secretion from non-tumor cells, leading to unwanted adverse side effects. Therefore, there are still significant challenges ahead to identify novel compounds and viable targets for selective inhibition or removal of tumor exosomes. In summary, growing evidence supports the notion that tumor-derived exosomes are potential suppressors of immune cells, including DCs, and targeting these extracellular vesicles may provide a new avenue for the better treatment of cancers.

\footnotetext{
Abbreviations

TDEs: Tumor-derived exosomes; mRNA: Messenger RNA; Fas-L: Fas ligand; PD-L1: Programmed death ligand1; NK cell: Natural killer cell; APCs: Antigen presenting cells; DCs: Dendritic cells; MDSCs: Myeloid-derived suppressor cells; pDCs: Plasmacytoid dendritic cells; cDCs: Conventional dendritic cells; Ag: Antigen; CD4: Cluster of differentiation 4; CD8: Cluster of differentiation 8; MHC-I: Major histocompatibility molecule 1; MHC-II: Major histocompatibility molecule 2; VEGF: Vascular endothelial growth factor; NF- kB: Nuclear factor kappaB; FLT3L: FMS-like tyrosine kinase 3 ligand; mAb: Monoclonal antibody; miRNA: MicroRNA; STAT3: Signal transducer and activator of transcription 3; PGE2: Prostaglandin E2; COX-1: Cyclooxygnase-1; COX-2: Cyclooxygenase 2; TGF- $\beta$ : Transforming growth factor beta; IL-6: Interleukin 6; Hsp70: Heat shock
} 
protein 70; Hsp72: Heat shock protein 72; MyD88: Myeloid differentiation primary response 88; S100A8: S100 calcium-binding protein A8; S100A9: S100 calcium-binding protein A9; HLA-G: Human leukocyte antigen G; CSC: Cancer stem cell; ATP: Adenosine three phosphate; PAMPs: Pathogen-associated molecular patterns; DAMPs: Damage-associated molecular patterns; TNFR: Tumor necrosis factor receptor; IL-1R: Interleukin 1 receptor; TLRs: Toll like receptors; CD40: Cluster of differentiation 40; CD80/86: Cluster of differentiation 80/86; BMDCs: Bone marrow-derived dendritic cells; HMGB1: High mobility group box 1 protein; TIM-3: T-cell immunoglobulin and mucin-domain containing-3; TIDCs: Tumor infiltrating dendritic cells; NSCLC: Non small-cell lung carcinoma; GBM: Glioblastoma multiforme; CSF: Cerebrospinal fluid; SIRPa: Signal regulatory protein a; SLN: Sentinel lymph node; EVs: Extracellular vesicles; Th1: T helper cell; IL-15: Interleukin 15; MIP-1 a/ B: Macrophage inflammatory protein 1alpha/beta; TNF-a: Tumor necrosis factor alpha; HIF-1: Hypoxia-inducible factor 1; IL-10: Interleukin 10; TAMs: Tumor-associated macrophages; HISLA: HIF-1a-stabilizing long noncoding RNA; B7-H1: B7 homolog 1; IDO: Indoleamine 2, 3-dioxygenase; TME: Tumor microenvironment; HLA-DR: Human leukocyte antigen - DR isotype; IFN-ץ: Interferon gamma; Tregs: Regulatory T cells; G-

CSF: Granulocyte-colony stimulating factor; AHR: Aryl hydrocarbon receptor A2AR: Adenosine A2A receptor; PPAR: Peroxisome proliferator-activated receptor; Rab27a: Ras-related GTPase 27a; nSMase2: Neutral sphingomyelinase 2; FDA: Food and Drug Administration

\section{Acknowledgements}

The authors would like to appreciate Isfahan University of Medical Sciences, Isfahan, Iran; and Cancer Research Center, Shahid Beheshti University of Medical Sciences, Tehran, Iran.

\section{Authors' contributions}

All authors contributed to writing this paper. All authors read and approved the final manuscript

\section{Funding}

Not applicable.

\section{Availability of data and materials}

Not applicable.

\section{Declarations}

\section{Ethics approval and consent to participate}

Not applicable.

\section{Consent for publication}

Not applicable.

\section{Competing interests}

The authors declare that they have no competing of interests.

\section{Author details}

${ }^{1}$ Department of Immunology, School of Medicine, Isfahan University of Medical Sciences, Isfahan, Iran. ${ }^{2}$ Cancer Research Center, Shahid Beheshti University of Medical Sciences, Tehran, Iran. ${ }^{3}$ Department of Biochemistry and Molecular Biology, LSUHSC School of Medicine, New Orleans, USA. ${ }^{4}$ Department of Immunology, School of Public Health, Tehran University of Medical Sciences, Tehran, Iran. ${ }^{5}$ Department of Tissue Engineering, School of Medicine, Shahroud University of Medical Sciences, Shahroud, Iran.

\section{Received: 13 January 2021 Accepted: 20 May 2021}

Published online: 02 June 2021

\section{References}

1. Mashouri L, Yousefi H, Aref AR, Mohammad Ahadi A, Molaei F, Alahari SK. Exosomes: composition, biogenesis, and mechanisms in cancer metastasis and drug resistance. Mol Cancer. 2019;18(1):75. https://doi.org/10.1186/s12 943-019-0991-5.

2. Mulcahy LA, Pink RC, Carter DRF. Routes and mechanisms of extracellular vesicle uptake. J Extracell Vesicles. 2014;3(1):24641. https://doi.org/10.3402/ jev.v3.24641.
3. Tittarelli A, Navarrete M, Lizana M, Hofmann-Vega F, Salazar-Onfray F. Hypoxic melanoma cells deliver microRNAs to dendritic cells and cytotoxic T lymphocytes through connexin-43 channels. Int J Mol Sci. 2020;21(20): 7567. https://doi.org/10.3390/ijms21207567.

4. Morrissey SM, Yan J. Exosomal PD-L1: roles in tumor progression and immunotherapy. Trends Cancer. 2020;6(7):550-8. https://doi.org/10.1016/j. trecan.2020.03.002

5. Bennit HRF, Gonda A, Oppegard LJ, Chi DP, Khan S, Wall NR. Uptake of lymphoma-derived exosomes by peripheral blood leukocytes. Blood Lymphatic Cancer: Targets Ther. 2017;7:9-23. https:/doi.org/10.2147/BLCTT.S130826.

6. Muller L, Simms P, Hong C-S, Nishimura MI, Jackson EK, Watkins SC, et al. Human tumor-derived exosomes (TEX) regulate Treg functions via cell surface signaling rather than uptake mechanisms. Oncoimmunology. 2017; 6(8):e1261243. https://doi.org/10.1080/2162402X.2016.1261243.

7. Whiteside TL. Immune modulation of T-cell and NK (natural killer) cell activities by TEXs (tumour-derived exosomes). Biochem Soc Trans. 2013; 41(1):245-51. https://doi.org/10.1042/BST20120265.

8. Benites BD, Alvarez MC, Saad STO. Small particles, big effects: the interplay between exosomes and dendritic cells in antitumor immunity and immunotherapy. Cells. 2019;8(12):1648. https://doi.org/10.3390/cells8121648.

9. Yang $\mathrm{C}$, Kim S-H, Bianco NR, Robbins PD. Tumor-derived exosomes confer antigen-specific immunosuppression in a murine delayed-type hypersensitivity model. PLoS One. 2011;6(8):e22517. https://doi.org/10.1371/ journal.pone.0022517.

10. Dudek AM, Martin S, Garg AD, Agostinis P. Immature, semi-mature, and fully mature dendritic cells: toward a DC-cancer cells interface that augments anticancer immunity. Front Immunol. 2013;4:438.

11. Yu S, Liu C, Su K, Wang J, Liu Y, Zhang L, et al. Tumor exosomes inhibit differentiation of bone marrow dendritic cells. J Immunol. 2007;178(11): 6867-75. https://doi.org/10.4049/jimmunol.178.11.6867.

12. Ning $Y$, Shen $K$, Wu Q, Sun $X$, Bai $Y$, Xie $Y$, et al. Tumor exosomes block dendritic cells maturation to decrease the $T$ cell immune response. Immunol Lett. 2018;199:36-43. https://doi.org/10.1016/j.imlet.2018.05.002.

13. Marton A, Vizler C, Kusz E, Temesfoi V, Szathmary Z, Nagy K, et al. Melanoma cell-derived exosomes alter macrophage and dendritic cell functions in vitro. Immunol Lett. 2012;148(1):34-8. https://doi.org/10.1016/j.imlet.2012. 07.006 .

14. Benites BD, Duarte ASS, ALF L, Santos I, Alvarez MC, de Morais Ribeiro LN, et al. Exosomes in the serum of acute myeloid leukemia patients induce dendritic cell tolerance: implications for immunotherapy. Vaccine. 2019; 37(11):1377-83. https://doi.org/10.1016/j.vaccine.2019.01.079.

15. Wang C, Huang X, Wu Y, Wang J, Li F, Guo G. Tumor cell-associated exosomes robustly elicit anti-tumor immune responses through modulating dendritic cell vaccines in lung tumor. Int J Biol Sci. 2020;16(4):633-43. https://doi.org/10.7150/ijbs.38414.

16. Salimu J, Webber J, Gurney M, Al-Taei S, Clayton A, Tabi Z. Dominant immunosuppression of dendritic cell function by prostate-cancer-derived exosomes. J Extracell Vesicles. 2017;6(1):1368823. https://doi.org/10.1080/2 0013078.2017 .1368823

17. Shortman K, Liu Y-J. Mouse and human dendritic cell subtypes. Nat Rev Immunol. 2002;2(3):151-61. https://doi.org/10.1038/nri746.

18. Wculek SK, Cueto FJ, Mujal AM, Melero I, Krummel MF, Sancho D. Dendritic cells in cancer immunology and immunotherapy. Nat Rev Immunol. 2020; 20(1):7-24. https://doi.org/10.1038/s41577-019-0210-z.

19. Veglia F, Gabrilovich DI. Dendritic cells in cancer: the role revisited. Curr Opin Immunol. 2017;45:43-51. https://doi.org/10.1016/j.coi.2017.01.002.

20. Gabrilovich D. Mechanisms and functional significance of tumour-induced dendritic-cell defects. Nat Rev Immunol. 2004;4(12):941-52. https://doi.org/1 $0.1038 /$ nri1498.

21. Tesone AJ, Svoronos N, Allegrezza MJ, Conejo-Garcia J. Pathological mobilization and activities of dendritic cells in tumor-bearing hosts: challenges and opportunities for immunotherapy of cancer. Front Immunol. 2013:4:435

22. Almand B, Resser JR, Lindman B, Nadaf S, Clark JI, Kwon ED, et al. Clinical significance of defective dendritic cell differentiation in cancer. Clin Cancer Res. 2000;6(5):1755-66

23. Zong J, Keskinov AA, Shurin GV, Shurin MR. Tumor-derived factors modulating dendritic cell function. Cancer Immunol Immunother. 2016; 65(7):821-33. https://doi.org/10.1007/s00262-016-1820-y.

24. Xiang X, Poliakov A, Liu C, Liu Y, Deng Z, Wang J, et al. Induction of myeloid-derived suppressor cells by tumor exosomes. Int J Cancer. 2009; 124(11):2621-33. https://doi.org/10.1002/ijc.24249. 
25. De Sanctis F, Bronte V, Ugel S. Tumor-Induced Myeloid-Derived Suppressor Cells. Myeloid Cells in Health and Disease: A Synthesis. 2017:833-56. https:// doi.org/10.1128/9781555819194.ch49.

26. Hargadon KM. Tumor-altered dendritic cell function: implications for antitumor immunity. Front Immunol. 2013;4:192.

27. Sombroek CC, Stam AG, Masterson AJ, Lougheed SM, Schakel MJ, Meijer CJ, et al. Prostanoids play a major role in the primary tumor-induced inhibition of dendritic cell differentiation. J Immunol. 2002;168(9):4333-43. https://doi. org/10.4049/jimmunol.168.9.4333.

28. Kim J, Hong SW, Kim S, Kim D, Hur DY, Jin DH, et al. Cyclooxygenase-2 expression is induced by celecoxib treatment in lung cancer cells and is transferred to neighbor cells via exosomes. Int J Oncol. 2018;52(2):613-20. https://doi.org/10.3892/ijo.2017.4227.

29. Mignot G, Chalmin F, Ladoire S, Rébé C, Ghiringhelli F, Xiang X, et al. Tumor exosome-mediated MDSC activation. Am J Pathol. 2011;178(3):1403-5. https://doi.org/10.1016/j.ajpath.2010.11.078.

30. Xiang X, Poliakov A, Liu C, Liu Y, Deng Z-b, Wang J, et al. Induction of myeloid-derived suppressor cells by tumor exosomes. Int J Cancer. 2009; 124(11):2621-33. https://doi.org/10.1002/ijc.24249.

31. Valenti R, Huber V, Filipazzi P, Pilla L, Sovena G, Villa A, et al. Human tumorreleased microvesicles promote the differentiation of myeloid cells with transforming growth factor- $\beta$-mediated suppressive activity on $T$ lymphocytes. Cancer Res. 2006;66(18):9290-8. https://doi.org/10.1158/00085472.CAN-06-1819.

32. Linton SS, Abraham T, Liao J, Clawson GA, Butler PJ, Fox T, et al. Tumorpromoting effects of pancreatic cancer cell exosomes on THP-1-derived macrophages. PLoS One. 2018;13(11):e0206759. https://doi.org/10.1371/ journal.pone.0206759.

33. Tian X, Shen H, Li Z, Wang T, Wang S. Tumor-derived exosomes, myeloidderived suppressor cells, and tumor microenvironment. J Hematol Oncol. 2019;12(1):84. https://doi.org/10.1186/s13045-019-0772-z.

34. Shen $Y$, Guo D, Weng L, Wang S, Ma Z, Yang Y, et al. Tumor-derived exosomes educate dendritic cells to promote tumor metastasis via HSP72/ HSP105-TLR2/TLR4 pathway. Oncoimmunology. 2017;6(12):e1362527. https://doi.org/10.1080/2162402X.2017.1362527.

35. Roccaro AM, Sacco A, Maiso P, Azab AK, Tai Y-T, Reagan M, et al. BM mesenchymal stromal cell-derived exosomes facilitate multiple myeloma progression. J Clin Invest. 2013;123(4):1542-55. https://doi.org/10.1172/ JCl66517.

36. Chalmin F, Ladoire S, Mignot G, Vincent J, Bruchard M, Remy-Martin J-P, et al. Membrane-associated Hsp72 from tumor-derived exosomes mediates STAT3-dependent immunosuppressive function of mouse and human myeloid-derived suppressor cells. J Clin Invest. 2010;120(2):457-71. https:// doi.org/10.1172/JCl40483.

37. Diao J, Yang $X$, Song $X$, Chen S, He Y, Wang Q, et al. Exosomal Hsp70 mediates immunosuppressive activity of the myeloid-derived suppressor cells via phosphorylation of Stat3. Med Oncol. 2015;32(2):35. https://doi. org/10.1007/s12032-014-0453-2.

38. Liu Y, Xiang X, Zhuang X, Zhang S, Liu C, Cheng Z, et al. Contribution of MyD88 to the tumor exosome-mediated induction of myeloid derived suppressor cells. Am J Pathol. 2010;176(5):2490-9. https://doi.org/10.2353/a jpath.2010.090777.

39. Grange C, Tapparo M, Tritta S, Deregibus MC, Battaglia A, Gontero P, et al Role of HLA-G and extracellular vesicles in renal cancer stem cell-induced inhibition of dendritic cell differentiation. BMC Cancer. 2015;15:1-11.

40. Banas R, Miller C, Guzik L, Zeevi A. Amnion-derived multipotent progenitor cells inhibit blood monocyte differentiation into mature dendritic cells. Cell Transplant. 2014;23(9):1111-25. https://doi.org/10.3727/096368913X670165.

41. Urosevic M, Dummer R. Human leukocyte antigen-G and cancer immunoediting. Cancer Res. 2008;68(3):627-30. https://doi.org/10.1158/ 0008-5472.CAN-07-2704.

42. Han L, Lam EW-F, Sun Y. Extracellular vesicles in the tumor microenvironment: old stories, but new tales. Mol Cancer. 2019;18(1):59. https://doi.org/10.1186/s12943-019-0980-8.

43. Ronquist KG. Extracellular vesicles and energy metabolism. Clin Chim Acta. 2019;488:116-21. https://doi.org/10.1016/j.cca.2018.10.044

44. Gottfried E, Kunz-Schughart LA, Ebner S, Mueller-Klieser W, Hoves S, Andreesen $\mathrm{R}$, et al. Tumor-derived lactic acid modulates dendritic cell activation and antigen expression. Blood. 2006;107(5):2013-21. https://doi. org/10.1182/blood-2005-05-1795.
45. Husain Z, Huang Y, Seth P, Sukhatme VP. Tumor-derived lactate modifies antitumor immune response: effect on myeloid-derived suppressor cells and NK cells. J Immunol. 2013;191(3):1486-95. https://doi.org/10.4049/ jimmunol.1202702.

46. Vasaturo A, Di Blasio S, Peeters DG, De Koning CC, De Vries J, Figdor C, et al. Clinical implications of co-inhibitory molecule expression in the tumor microenvironment for DC vaccination: a game of stop and go. Front Immunol. 2013:4:417.

47. Truxova I, Kasikova L, Hensler M, Skapa P, Laco J, Pecen L, et al. Mature dendritic cells correlate with favorable immune infiltrate and improved prognosis in ovarian carcinoma patients. J Immunother Cancer. 2018;6:1-13.

48. Bergeron A, El Hage F, Kambouchner M, Lecossier D, Tazi A. Characterisation of dendritic cell subsets in lung cancer micro-environments. Eur Respir J. 2006;28(6):1170-7. https://doi.org/10.1183/09031936.06.00114205.

49. Alshamsan A, Hamdy S, Das SDS, Lavasanifar A, Samuel J, El-Kadi AO. Validation of bone marrow derived dendritic cells as an appropriate model to study tumor-mediated suppression of DC maturation through STAT3 hyperactivation. J Pharm Pharm Sci. 2010;13(1):21-6. https://doi.org/10.1 8433/J37598.

50. Maus RL, Jakub JW, Nevala WK, Christensen TA, Noble-Orcutt K, Sachs Z, et al. Human melanoma-derived extracellular vesicles regulate dendritic cell maturation. Front Immunol. 2017:8:358.

51. Chiba S, Baghdadi M, Akiba H, Yoshiyama H, Kinoshita I, Dosaka-Akita H, et al. Tumor-infiltrating DCs suppress nucleic acid-mediated innate immune responses through interactions between the receptor TIM-3 and the alarmin HMGB1. Nat Immunol. 2012;13(9):832-42. https://doi.org/10.1038/ni.2376.

52. Gao J, Qiu X, Li X, Fan H, Zhang F, Lv T, et al. Expression profiles and clinical value of plasma exosomal Tim-3 and Galectin-9 in non-small cell lung cancer. Biochem Biophys Res Commun. 2018;498(3):409-15. https://doi. org/10.1016/j.bbrc.2018.02.114.

53. Wang $M$, Cai $Y$, Peng $Y, X u B$, Hui W, Jiang $Y$. Exosomal LGALS9 in the cerebrospinal fluid of glioblastoma patients suppressed dendritic cell antigen presentation and cytotoxic T-cell immunity. Cell Death Dis. 2020;11: $1-16$.

54. Xu MM, Pu Y, Han D, Shi Y, Cao X, Liang H, et al. Dendritic cells but not macrophages sense tumor mitochondrial DNA for cross-priming through signal regulatory protein a signaling. Immunity. 2017;47:363-373. e365.

55. Koh E, Lee EJ, Nam GH, Hong Y, Cho E, Yang Y, et al. Exosome-SIRPa, a CD47 blockade increases cancer cell phagocytosis. Biomaterials. 2017;121: 121-9. https://doi.org/10.1016/j.biomaterials.2017.01.004.

56. Kaur S, Elkahloun AG, Arakelyan A, Young L, Myers TG, Otaizo-Carrasquero F, et al. CD63, MHC class 1, and CD47 identify subsets of extracellular vesicles containing distinct populations of noncoding RNAs. Sci Rep. 2018;8:1-17.

57. Kibria G, Ramos EK, Lee KE, Bedoyan S, Huang S, Samaeekia R, et al. A rapid, automated surface protein profiling of single circulating exosomes in human blood. Sci Rep. 2016;6(1):36502. https://doi.org/10.1038/srep36502.

58. Willingham SB, Volkmer J-P, Gentles AJ, Sahoo D, Dalerba P, Mitra SS, et al. The CD47-signal regulatory protein alpha (SIRPa) interaction is a therapeutic target for human solid tumors. Proc Natl Acad Sci. 2012;109(17):6662-7. https://doi.org/10.1073/pnas.1121623109.

59. Whiteside TL. Therapeutic targeting of oncogenic KRAS in pancreatic cancer by engineered exosomes. Transl Cancer Res. 2017;6(S9):S1406-8. https://doi. org/10.21037/tcr.2017.10.32.

60. Chauhan S, Danielson S, Clements V, Edwards N, Ostrand-Rosenberg S, Fenselau C. Surface glycoproteins of exosomes shed by myeloid-derived suppressor cells contribute to function. J Proteome Res. 2017;16(1):238-46. https://doi.org/10.1021/acs.jproteome.6b00811.

61. Groth C, Hu X, Weber R, Fleming V, Altevogt P, Utikal J, et al. Immunosuppression mediated by myeloid-derived suppressor cells (MDSCs) during tumour progression. Br J Cancer. 2019;120(1):16-25. https://doi.org/1 0.1038/s41416-018-0333-1.

62. Poschke I, Mao Y, Adamson L, Salazar-Onfray F, Masucci G, Kiessling R. Myeloid-derived suppressor cells impair the quality of dendritic cell vaccines. Cancer Immunol Immunother. 2012;61(6):827-38. https://doi.org/1 0.1007/s00262-011-1143-y.

63. Maus RL, Jakub JW, Hieken TJ, Nevala WK, Christensen TA, Sutor SL, et al. Identification of novel, immune-mediating extracellular vesicles in human lymphatic effluent draining primary cutaneous melanoma. Oncoimmunology. 2019;8(12):e1667742. https://doi.org/10.1080/2162402X.2 019.1667742 . 
64. Hsu Y-L, Hung J-Y, Tsai E-M, Wu C-Y, Ho Y-W, Jian S-F, et al. Benzyl butyl phthalate increases the chemoresistance to doxorubicin/cyclophosphamide by increasing breast cancer-associated dendritic cell-derived CXCL1/GROa and S100A8/A9. Oncol Rep. 2015;34(6):2889-900. https://doi.org/10.3892/ or.2015.4307.

65. Sevko A, Michels $T$, Vrohlings $M$, Umansky $L$, Beckhove $P$, Kato $M$, et al. Antitumor effect of paclitaxel is mediated by inhibition of myeloid-derived suppressor cells and chronic inflammation in the spontaneous melanoma model. J Immunol. 2013;190(5):2464-71. https://doi.org/10.4049/jimmunol.12 02781.

66. Shurin MR, Naiditch $H$, Gutkin DW, Umansky V, Shurin GV ChemolmmunoModulation: immune regulation by the antineoplastic chemotherapeutic agents. Curr Med Chem. 2012:19:1792-803.

67. Prieto D, Sotelo N, Seija N, Sernbo S, Abreu C, Durán R, et al. S100-A9 protein in exosomes from chronic lymphocytic leukemia cells promotes NFKB activity during disease progression. Blood, J Am Soc Hematol. 2017;130: $777-88$.

68. Rong L, Li R, Li S, Luo R. Immunosuppression of breast cancer cells mediated by transforming growth factor- $\beta$ in exosomes from cancer cells. Oncol Lett. 2016;11(1):500-4. https://doi.org/10.3892/ol.2015.3841.

69. Bretz NP, Ridinger J, Rupp A-K, Rimbach K, Keller S, Rupp C, et al. Body fluid exosomes promote secretion of inflammatory cytokines in monocytic cells via toll-like receptor signaling. J Biol Chem. 2013;288(51):36691-702. https:// doi.org/10.1074/jbc.M113.512806

70. Taghikhani A, Hassan ZM, Ebrahimi M, Moazzeni SM. microRNA modified tumor-derived exosomes as novel tools for maturation of dendritic cells. J Cell Physiol. 2019;234(6):9417-27. https://doi.org/10.1002/jcp.27626.

71. Van Obberghen-Schilling E, Roche NS, Flanders KC, Sporn MB, Roberts AB. Transforming growth factor beta 1 positively regulates its own expression in normal and transformed cells. J Biol Chem. 1988;263(16):7741-6. https://doi. org/10.1016/S0021-9258(18)68561-8

72. Gonzalez-Junca A, Driscoll KE, Pellicciotta I, Du S, Lo CH, Roy R, et al. Autocrine TGF $\beta$ is a survival factor for monocytes and drives immunosuppressive lineage commitment. Cancer Immunol Res. 2019;7(2): 306-20. https://doi.org/10.1158/2326-6066.CIR-18-0310.

73. Esebanmen $\mathrm{GE}$, Langridge $\mathrm{WH}$. The role of TGF-beta signaling in dendritic cell tolerance. Immunol Res. 2017;65(5):987-94. https://doi.org/10.1007/s12 026-017-8944-9.

74. Wang $Y$, Yi J, Chen $X$, Zhang Y, Xu M, Yang Z. The regulation of cancer cel migration by lung cancer cell-derived exosomes through TGF- $\beta$ and IL-10. Oncol Lett. 2016;11(2):1527-30. https://doi.org/10.3892/ol.2015.4044.

75. Qian Y, Wang X, Li Y, Cao Y, Chen X. Extracellular ATP a new player in cancer metabolism: NSCLC cells internalize ATP in vitro and in vivo using multiple endocytic mechanisms. Mol Cancer Res. 2016;14(11):1087-96. https://doi.org/10.1158/1541-7786.MCR-16-0118.

76. Chen F, Chen J, Yang L, Liu J, Zhang X, Zhang Y, et al. Extracellular vesiclepackaged HIF-1a-stabilizing IncRNA from tumour-associated macrophages regulates aerobic glycolysis of breast cancer cells. Nat Cell Biol. 2019;21(4): 498-510. https://doi.org/10.1038/s41556-019-0299-0.

77. Gabrilovich DI, Corak J, Ciernik IF, Kavanaugh D, Carbone DP. Decreased antigen presentation by dendritic cells in patients with breast cancer. Clin Cancer Res. 1997;3(3):483-90.

78. Krempski J, Karyampudi L, Behrens MD, Erskine CL, Hartmann L, Dong H, et al. Tumor-infiltrating programmed death receptor-1+ dendritic cells mediate immune suppression in ovarian cancer. J Immunol. 2011;186(12): 6905-13. https://doi.org/10.4049/jimmunol.1100274.

79. Scarlett UK, Rutkowski MR, Rauwerdink AM, Fields J, Escovar-Fadul X, Baird J, et al. Ovarian cancer progression is controlled by phenotypic changes in dendritic cells. J Exp Med. 2012;209(3):495-506. https://doi.org/10.1084/ jem.20111413.

80. Javeed N, Gustafson MP, Dutta SK, Lin Y, Bamlet WR, Oberg AL, et al. Immunosuppressive CD14+ HLA-DRlo/neg monocytes are elevated in pancreatic cancer and "primed" by tumor-derived exosomes. Oncoimmunology. 2017;6(1): e1252013. https://doi.org/10.1080/2162402X.2016.1252013.

81. Domenis R, Cesselli D, Toffoletto B, Bourkoula E, Caponnetto F, Manini I, et al. Systemic T cells immunosuppression of glioma stem cell-derived exosomes is mediated by monocytic myeloid-derived suppressor cells. PLoS One. 2017;12(1):e0169932. https://doi.org/10.1371/journal.pone.0169932.

82. Himes BT, Peterson TE, de Mooij T, Garcia LMC, Jung MY, Uhm S, et al. The role of extracellular vesicles and PD-L1 in glioblastoma-mediated immunosuppressive monocyte induction. Neuro-Oncology. 2020;22(7):96778. https://doi.org/10.1093/neuonc/noaa029.

83. Lim TS, Chew V, Sieow JL, Goh S, Yeong JP, Soon AL, et al. PD-1 expression on dendritic cells suppresses CD8(+) T cell function and antitumor immunity. Oncoimmunology. 2016;5(3):e1085146. https://doi.org/10.1080/21 62402X.2015.1085146.

84. Diaz AA. Exosomal PD-L1 induces immunosuppressive nonclassical monocytes. Neuro-oncology.2020;22(7):901-2. https://doi.org/10.1093/ neuonc/noaa100.

85. Yang Y, Li C-W, Chan L-C, Wei Y, Hsu J-M, Xia W, et al. Exosomal PD-L1 harbors active defense function to suppress T cell killing of breast cancer cells and promote tumor growth. Cell Res. 2018;28(8):862-4. https://doi. org/10.1038/s41422-018-0060-4.

86. Tang $Y$, Zhang P, Wang $Y$, Wang J, Su M, Wang Y, et al. The biogenesis, biology, and clinical significance of exosomal PD-L1 in cancer. Front Immunol. 2020;11:604. https://doi.org/10.3389/fimmu.2020.00604.

87. Gabrusiewicz K, Li X, Wei J, Hashimoto Y, Marisetty AL, Ott M, et al. Glioblastoma stem cell-derived exosomes induce M2 macrophages and PDL1 expression on human monocytes. Oncoimmunology. 2018;7(4):e1412909. https://doi.org/10.1080/2162402X.2017.1412909.

88. Haderk F, Schulz R, Iskar M, Cid LL, Worst T, Willmund KV, et al. Tumorderived exosomes modulate PD-L1 expression in monocytes. Sci Immunol. 2017;2(13):eaah5509. https://doi.org/10.1126/sciimmunol.aah5509.

89. Peng Q, Qiu X, Zhang Z, Zhang S, Zhang Y, Liang Y, et al. PD-L1 on dendritic cells attenuates $T$ cell activation and regulates response to immune checkpoint blockade. Nat Commun. 2020;11:1-8.

90. Larrain MI, Rabassa ME, Lacunza E, Barbera A, Cretón A, Segal-Eiras A, et al. IDO is highly expressed in breast cancer and breast cancer-derived circulating microvesicles and associated to aggressive types of tumors by in silico analysis. Tumor Biol. 2014;35(7):6511-9. https://doi.org/10.1007/s13277014-1859-3.

91. Zhou C, Zhang Y, Yan R, Huang L, Mellor AL, Yang Y, et al. Exosome-derived miR-142-5p remodels lymphatic vessels and induces IDO to promote immune privilege in the tumour microenvironment. Cell Death Differ. 2021; 28(2):715-29. https://doi.org/10.1038/s41418-020-00618-6.

92. Tohumeken S, Baur R, Böttcher M, Stoll A, Loschinski R, Panagiotidis K, et al. Palmitoylated proteins on AML-derived extracellular vesicles promote myeloid-derived suppressor cell differentiation via TLR2/Akt/mTOR signaling. Cancer Res. 2020;80(17):3663-76. https://doi.org/10.1158/0008-5472.CAN-200024.

93. He J-G, Xie Q-L, Li B-B, Zhou L, Yan D. Exosomes derived from IDO1overexpressing rat bone marrow mesenchymal stem cells promote immunotolerance of cardiac allografts. Cell Transplant. 2018;27(11):1657-83. https://doi.org/10.1177/0963689718805375.

94. Munn DH, Mellor AL. Indoleamine 2, 3-dioxygenase and tumor-induced tolerance. J Clin Invest. 2007;117(5):1147-54. https://doi.org/10.1172/JCl31178.

95. Nguyen NT, Kimura A, Nakahama T, Chinen I, Masuda K, Nohara K, et al. Aryl hydrocarbon receptor negatively regulates dendritic cell immunogenicity via a kynurenine-dependent mechanism. Proc Natl Acad Sci. 2010;107(46): 19961-6. https://doi.org/10.1073/pnas.1014465107.

96. Munn DH, Mellor AL. IDO in the tumor microenvironment: inflammation, counter-regulation, and tolerance. Trends Immunol. 2016;37(3):193-207. https://doi.org/10.1016/j.it.2016.01.002.

97. Bianco NR, Kim SH, Ruffner MA, Robbins PD. Exosomes from IDO+ DC are therapeutic in CIA and DTH disease models. Arthritis Rheum. 2009;60(2): 380-9. https://doi.org/10.1002/art.24229.

98. Azambuja JH, Ludwig N, Yerneni SS, Braganhol E, Whiteside TL. Arginase-1+ exosomes from reprogrammed macrophages promote glioblastoma progression. Int J Mol Sci. 2020;21(11):3990. https://doi.org/10.3390/ ijms21113990.

99. Czystowska-Kuzmicz M, Sosnowska A, Nowis D, Ramji K, Szajnik M, Chlebowska-Tuz J, et al. Small extracellular vesicles containing arginase-1 suppress T-cell responses and promote tumor growth in ovarian carcinoma. Nat Commun. 2019;10:1-16.

100. Czystowska-Kuźmicz M, Szajnik M, Gruca S, Stefanowicz A, Gołąb M. 40P Role of tumor-derived exosomal arginase- 1 in avoiding immune responses by ovarian cancer. Ann Oncol. 2016;27:mdw525-40.

101. Zou S, Wang X, Liu P, Ke C, Xu S. Arginine metabolism and deprivation in cancer therapy. Biomed Pharmacother. 2019;118:109210. https://doi.org/10.1 016/j.biopha.2019.109210. 
102. Narita Y, Kitamura H, Wakita D, Sumida K, Masuko K, Terada S, et al. The key role of IL-6-arginase cascade for inducing dendritic cell-dependent CD4+ T cell dysfunction in tumor-bearing mice. J Immunol. 2013;190(2):812-20. https://doi.org/10.4049/jimmunol.1103797.

103. Norian LA, Rodriguez PC, O'Mara LA, Zabaleta J, Ochoa AC, Cella M, et al. Tumor-infiltrating regulatory dendritic cells inhibit CD8+ T cell function via L-arginine metabolism. Cancer Res. 2009;69(7):3086-94. https://doi.org/10.11 58/0008-5472.CAN-08-2826.

104. Song $X$, Zhang Y, Zhang L, Song W, Shi L. Hypoxia enhances indoleamine 2, 3-dioxygenase production in dendritic cells. Oncotarget. 2018;9(14):1157280. https://doi.org/10.18632/oncotarget.24098.

105. Allard B, Longhi MS, Robson SC, Stagg J. The ectonucleotidases CD 39 and CD 73: novel checkpoint inhibitor targets. Immunol Rev. 2017;276(1):121-44. https://doi.org/10.1111/imr.12528

106. Herber DL, Cao W, Nefedova Y, Novitskiy SV, Nagaraj S, Tyurin VA, et al. Lipid accumulation and dendritic cell dysfunction in cancer. Nat Med. 2010; 16(8):880-6. https://doi.org/10.1038/nm.2172.

107. Cao W, Ramakrishnan R, Tuyrin VA, Veglia F, Condamine T, Amoscato A, et al. Oxidized lipids block antigen cross-presentation by dendritic cells in cancer. J Immunol. 2014;192(6):2920-31. https://doi.org/10.4049/ jimmunol.1302801.

108. Veglia F, Tyurin VA, Mohammadyani D, Blasi M, Duperret EK, Donthireddy L, et al. Lipid bodies containing oxidatively truncated lipids block antigen cross-presentation by dendritic cells in cancer. Nat Commun. 2017;8:1-16.

109. Yin X, Zeng W, Wu B, Wang L, Wang Z, Tian H, et al. PPARa inhibition overcomes tumor-derived exosomal lipid-induced dendritic cell dysfunction. Cell Rep. 2020;33(3):108278. https://doi.org/10.1016/j.celrep.2020.108278.

110. Liu H, Chen L, Peng Y, Yu S, Liu J, Wu L, et al. Dendritic cells loaded with tumor derived exosomes for cancer immunotherapy. Oncotarget. 2018;9(2): 2887-94. https://doi.org/10.18632/oncotarget.20812.

111. Xu Z, Zeng S, Gong Z, Yan Y. Exosome-based immunotherapy: a promising approach for cancer treatment. Mol Cancer. 2020;19:1-16.

112. Gu X, Erb U, Büchler MW, Zöller M. Improved vaccine efficacy of tumor exosome compared to tumor lysate loaded dendritic cells in mice. Int J Cancer. 2015;136(4):E74-84. https://doi.org/10.1002/ijc.29100.

113. Huang F, Wan J, Hu W, Hao S. Enhancement of anti-leukemia immunity by leukemia-derived exosomes via downregulation of TGF- $\beta 1$ expression. Cell Physiol Biochem. 2017:44(1):240-54. https://doi.org/10.1159/000484677.

114. Li S, Xu J, Qian J, Gao X. Engineering extracellular vesicles for cancer therapy: recent advances and challenges in clinical translation. Biomater Sci. 2020;8(24):6978-91. https://doi.org/10.1039/D0BM01385D.

115. Huang F, Wan J, Hao S, Deng X, Chen L, Ma L. TGF- $\beta 1$-silenced leukemia cell-derived exosomes target dendritic cells to induce potent anti-leukemic immunity in a mouse model. Cancer Immunol Immunother. 2017;66(10): 1321-31. https://doi.org/10.1007/s00262-017-2028-5.

116. Rossowska J, Anger N, Wegierek K, Szczygieł A, Mierzejewska J, Milczarek M, et al. Antitumor potential of extracellular vesicles released by genetically modified murine colon carcinoma cells with overexpression of interleukin12 and shRNA for TGF-B1. Front Immunol. 2019;10:211. https://doi.org/10.33 89/fimmu.2019.00211.

117. Hong C-S, Sharma P, Yerneni SS, Simms P, Jackson EK, Whiteside TL, et al. Circulating exosomes carrying an immunosuppressive cargo interfere with cellular immunotherapy in acute myeloid leukemia. Sci Rep. 2017;7:1-10.

118. Chen Z, You L, Wang L, Huang X, Liu H, Ying Wei J, et al. Dual effect of DLBCL-derived EXOs in lymphoma to improve DC vaccine efficacy in vitro while favor tumorgenesis in vivo. J Exp Clin Cancer Res. 2018;37:1-18.

119. Shimada Y, Matsubayashi J, Kudo Y, Maehara S, Takeuchi S, Hagiwara M, et al. Serum-derived exosomal PD-L1 expression to predict anti-PD-1 response and in patients with non-small cell lung cancer. Sci Rep. 2021;11: $1-10$

120. Chen G, Huang AC, Zhang W, Zhang G, Wu M, Xu W, et al. Exosomal PD-L1 contributes to immunosuppression and is associated with anti-PD-1 response. Nature. 2018;560(7718):382-6. https://doi.org/10.1038/s41586-0180392-8.

121. Martinez VG, O'Neill S, Salimu J, Breslin S, Clayton A, Crown J, et al. Resistance to HER2-targeted anti-cancer drugs is associated with immune evasion in cancer cells and their derived extracellular vesicles. Oncoimmunology. 2017;6(12):e1362530. https://doi.org/10.1080/2162402X.2 017.1362530 .

122. Ciravolo V, Huber V, Ghedini GC, Venturelli E, Bianchi F, Campiglio M, et al. Potential role of HER2-overexpressing exosomes in countering trastuzumab- based therapy. J Cell Physiol. 2012;227(2):658-67. https://doi.org/10.1002/ jcp.22773.

123. Aung T, Chapuy B, Vogel D, Wenzel D, Oppermann M, Lahmann M, et al. Exosomal evasion of humoral immunotherapy in aggressive B-cell lymphoma modulated by ATP-binding cassette transporter A3. Proc Natl Acad Sci. 2011;108(37):15336-41. https://doi.org/10.1073/pnas.1102855108.

124. Mostafazadeh M, Samadi N, Kahroba H, Baradaran B, Haiaty S, Nouri M. Potential roles and prognostic significance of exosomes in cancer drug resistance. Cell Biosci. 2021;11(1):1-15. https://doi.org/10.1186/s13578-02000515-y.

125. Yousafzai NA, Wang H, Wang Z, Zhu Y, Zhu L, Jin H, et al. Exosome mediated multidrug resistance in cancer. Am J Cancer Res. 2018;8:2210.

126. Dong X, Bai X, Ni J, Zhang H, Duan W, Graham P, et al. Exosomes and breast cancer drug resistance. Cell Death Dis. 2020;11:1-14.

127. Poggio M, Hu T, Pai C-C, Chu B, Belair CD, Chang A, et al. Suppression of exosomal PD-L1 induces systemic anti-tumor immunity and memory. Cell. 2019:177:414-427. e413.

128. Ricklefs FL, Alayo Q, Krenzlin H, Mahmoud AB, Speranza MC, Nakashima H, et al. Immune evasion mediated by PD-L1 on glioblastoma-derived extracellular vesicles. Sci Adv. 2018;4:eaar2766.

129. Jorfi S, Ansa-Addo EA, Kholia S, Stratton D, Valley S, Lange S, et al. Inhibition of microvesiculation sensitizes prostate cancer cells to chemotherapy and reduces docetaxel dose required to limit tumor growth in vivo. Sci Rep. 2015;5(1):13006. https://doi.org/10.1038/srep13006.

130. Marleau AM, Chen C-S, Joyce JA, Tullis RH. Exosome removal as a therapeutic adjuvant in cancer. J Transl Med. 2012;10:1-12.

131. Trajkovic K, Hsu C, Chiantia S, Rajendran L, Wenzel D, Wieland F, et al. Ceramide triggers budding of exosome vesicles into multivesicular endosomes. Science. 2008;319(5867):1244-7. https://doi.org/10.1126/ science.1153124.

132. Menck K, Sönmezer C, Worst TS, Schulz M, Dihazi GH, Streit F, et al. Neutral sphingomyelinases control extracellular vesicles budding from the plasma membrane. J Extracell Vesicles. 2017;6(1):1378056. https://doi.org/10.1080/2 0013078.2017 .1378056

133. Ostrowski M, Carmo NB, Krumeich S, Fanget I, Raposo G, Savina A, et al. Rab27a and Rab27b control different steps of the exosome secretion pathway. Nat Cell Biol. 2010;12(1):19-30. https://doi.org/10.1038/ncb2000.

134. Blanc L, Vidal M. New insights into the function of Rab GTPases in the context of exosomal secretion. Small GTPases. 2018;9(1-2):95-106. https:// doi.org/10.1080/21541248.2016.1264352.

135. Catalano M, O'Driscoll L. Inhibiting extracellular vesicles formation and release: a review of EV inhibitors. J Extracell Vesicles. 2020;9(1):1703244. https://doi.org/10.1080/20013078.2019.1703244.

136. Datta A, Kim H, Lal M, McGee L, Johnson A, Moustafa AA, et al. Manumycin A suppresses exosome biogenesis and secretion via targeted inhibition of Ras/Raf/ERK1/2 signaling and hnRNP H1 in castration-resistant prostate cancer cells. Cancer Lett. 2017:408:73-81. https://doi.org/10.1016/j.canlet.201 7.08.020.

137. Li J, Liu K, Liu Y, Xu Y, Zhang F, Yang H, et al. Exosomes mediate the cell-tocell transmission of IFN-a-induced antiviral activity. Nat Immunol. 2013;14(8): 793-803. https://doi.org/10.1038/ni.2647.

138. Takahashi A, Okada R, Nagao K, Kawamata Y, Hanyu A, Yoshimoto S, et al. Exosomes maintain cellular homeostasis by excreting harmful DNA from cells. Nat Commun. 2017:8:1-16.

139. Figuera-Losada M, Stathis M, Dorskind JM, Thomas AG, Bandaru WR, Yoo SW, et al. Cambinol, a novel inhibitor of neutral sphingomyelinase 2 shows neuroprotective properties. PLoS One. 2015;10(5):e0124481. https://doi.org/1 0.1371/journal.pone.0124481.

140. Barbone AG, Jackson AC, Ritchie DM, Argentieri DC. [19] robotic assay of sphingomyelinase activity for high throughput screening. Methods Enzymol. 2000;311:168-76. https://doi.org/10.1016/S0076-6879(00)11078-X.

141. Krut O, Wiegmann K, Kashkar H, Yazdanpanah B, Krönke M. Novel tumor necrosis factor-responsive mammalian neutral sphingomyelinase-3 is a Ctail-anchored protein. J Biol Chem. 2006;281(19):13784-93. https://doi.org/1 0.1074/jbc.M511306200.

142. Rojas C, Barnaeva E, Thomas AG, Hu X, Southall N, Marugan J, et al. DPTIP, a newly identified potent brain penetrant neutral sphingomyelinase 2 inhibitor, regulates astrocyte-peripheral immune communication following brain inflammation. Sci Rep. 2018;8:1-11.

143. Datta A, Kim H, McGee L, Johnson AE, Talwar S, Marugan J, et al. Highthroughput screening identified selective inhibitors of exosome biogenesis 
and secretion: a drug repurposing strategy for advanced cancer. Sci Rep. 2018;8:1-13.

144. Zhang H. Design, synthesis and activity evaluation of novel exosome inhibitors; 2020

145. Sella A, Kilbourn R, Amato R, Bui C, Zukiwski AA, Ellerhorst J, et al. Phase II study of ketoconazole combined with weekly doxorubicin in patients with androgen-independent prostate cancer. J Clin Oncol. 1994;12(4):683-8. https://doi.org/10.1200/JCO.1994.12.4.683.

146. Andreopoulou E, Vigoda IS, Valero V, Hershman DL, Raptis G, Vahdat LT, et al. Phase I-II study of the farnesyl transferase inhibitor tipifarnib plus sequential weekly paclitaxel and doxorubicin-cyclophosphamide in HER2/ neu-negative inflammatory carcinoma and non-inflammatory estrogen receptor-positive breast carcinoma. Breast Cancer Res Treat. 2013;141(3): 429-35. https://doi.org/10.1007/s10549-013-2704-x.

147. Sparano JA, Moulder S, Kazi A, Coppola D, Negassa A, Vahdat L, et al. Phase II trial of tipifarnib plus neoadjuvant doxorubicin-cyclophosphamide in patients with clinical stage IIB-IIIC breast cancer. Clin Cancer Res. 2009;15(8): 2942-8. https://doi.org/10.1158/1078-0432.CCR-08-2658.

148. Ho AL, Hanna GJ, Scholz CR, Gualberto A, Park SH. Preliminary activity of tipifarnib in tumors of the head and neck, salivary gland and urothelial tract with HRAS mutations. J Clin Oncol. 2020;38(15_suppl):6504. https://doi.org/1 0.1200/JCO.2020.38.15_suppl.6504.

149. Im E-J, Lee C-H, Moon P-G, Rangaswamy GG, Lee B, Lee JM, et al. Sulfisoxazole inhibits the secretion of small extracellular vesicles by targeting the endothelin receptor A. Nat Commun. 2019;10:1-17.

150. Khan FM, Saleh E, Alawadhi H, Harati R, Zimmermann W-H, El-Awady R. Inhibition of exosome release by ketotifen enhances sensitivity of cancer cells to doxorubicin. Cancer Biol Ther. 2018;19(1):25-33. https://doi.org/10.1 080/15384047.2017.1394544.

151. Kosgodage US, Mould R, Henley AB, Nunn AV, Guy GW, Thomas EL, et al. Cannabidiol (CBD) is a novel inhibitor for exosome and microvesicle (EMV) release in cancer. Front Pharmacol. 2018;9:889. https://doi.org/10.3389/fpha r.2018.00889.

152. Kosgodage US, Uysal-Onganer P, MacLatchy A, Mould R, Nunn AV, Guy GW, et al. Cannabidiol affects extracellular vesicle release, miR21 and miR126, and reduces prohibitin protein in glioblastoma multiforme cells. Trans Oncol. 2019;12(3):513-22. https://doi.org/10.1016/j.tranon.2018.12.004.

153. Luciani F, Spada M, De Milito A, Molinari A, Rivoltini L, Montinaro A, et al. Effect of proton pump inhibitor pretreatment on resistance of solid tumors to cytotoxic drugs. J Natl Cancer Inst. 2004;96(22):1702-13. https://doi.org/1 0.1093/jnci/djh305

154. Taylor S, Spugnini EP, Assaraf YG, Azzarito T, Rauch C, Fais S. Microenvironment acidity as a major determinant of tumor chemoresistance: proton pump inhibitors (PPIs) as a novel therapeutic approach. Drug Resist Updat. 2015;23:69-78. https://doi.org/10.1016/.jrup.2 015.08.004.

155. Kosgodage US, Trindade RP, Thompson PR, Inal JM, Lange S. Chloramidine/ bisindolylmaleimide---mediated inhibition of exosome and microvesicle release and enhanced efficacy of cancer chemotherapy. Int J Mol Sci. 2017; 18(5):1007. https://doi.org/10.3390/ijms18051007.

156. Roseblade A, Luk F, Ung A, Bebawy M. Targeting microparticle biogenesis: a novel approach to the circumvention of cancer multidrug resistance. Curr Cancer Drug Targets. 2015;15(3):205-14. https://doi.org/10.2174/156800961 5666150225121508

157. Liu J, Zhang Y, Liu A, Wang J, Li L, Chen $X$, et al. Distinct dasatinib-induced mechanisms of apoptotic response and exosome release in imatinibresistant human chronic myeloid leukemia cells. Int J Mol Sci. 2016;17(4): 531. https://doi.org/10.3390/ijms17040531

158. Huang M-B, Gonzalez RR, Lillard J, Bond VC. Secretion modification regionderived peptide blocks exosome release and mediates cell cycle arrest in breast cancer cells. Oncotarget. 2017;8(7):11302-15. https://doi.org/10.1 8632/oncotarget.14513.

159. Thyagarajan A, Kadam SM, Liu L, Kelly LE, Rapp CM, Chen Y, et al. Gemcitabine induces microvesicle particle release in a platelet-activating factor-receptor-dependent manner via modulation of the MAPK pathway in pancreatic cancer cells. Int J Mol Sci. 2019:20:32.

160. Nishida-Aoki N, Tominaga N, Takeshita F, Sonoda H, Yoshioka Y, Ochiya T. Disruption of circulating extracellular vesicles as a novel therapeutic strategy against cancer metastasis. Mol Ther. 2017;25(1):181-91. https://doi.org/10.1 016/j.ymthe.2016.10.009.
161. Harada T, Yamamoto H, Kishida S, Kishida M, Awada C, Takao T, et al. Wnt5b-associated exosomes promote cancer cell migration and proliferation. Cancer Sci. 2017;108(1):42-52. https://doi.org/10.1111/cas.13109.

162. Pessolano E, Belvedere R, Bizzarro V, Franco P, De Marco I, Porta A, et al. Annexin A1 may induce pancreatic cancer progression as a key player of extracellular vesicles effects as evidenced in the in vitro MIA PaCa-2 model system. Int J Mol Sci. 2018;19(12):3878. https://doi.org/10.3390/ijms19123878.

163. Guo J, Jayaprakash P, Dan J, Wise P, Jang G-B, Liang C, et al. PRAS40 connects microenvironmental stress signaling to exosome-mediated secretion. Mol Cell Biol. 2017;37(19). https://doi.org/10.1128/MCB.00171-17.

164. Featherby S, Madkhali Y, Maraveyas A, Ettelaie C. Apixaban suppresses the release of TF-positive microvesicles and restrains cancer cell proliferation through directly inhibiting TF-fVlla activity. Thromb Haemost. 2019;119(9): 1419-32. https://doi.org/10.1055/s-0039-1692682.

165. Gabrilovich DI, Chen HL, Girgis KR, Cunningham HT, Meny GM, Nadaf S, et al. Production of vascular endothelial growth factor by human tumors inhibits the functional maturation of dendritic cells. Nat Med. 1996;2(10): 1096-103. https://doi.org/10.1038/nm1096-1096.

166. Gabrilovich D, Ishida T, Oyama T, Ran S, Kravtsov V, Nadaf S, et al. Vascular endothelial growth factor inhibits the development of dendritic cells and dramatically affects the differentiation of multiple hematopoietic lineages In Vivo: Presented in part at the Keystone Symposium "Cellular and Molecular Biology of Dendritic Cells," Santa Fe, NM, March 3-9, 1998, and at the annual meeting of the American Association for Cancer Research, March 28-April 1, 1998. Blood, J Am Soc Hematol. 1998;92:4150-66.

167. Ishida T, Oyama T, Carbone DP, Gabrilovich DI. Defective function of Langerhans cells in tumor-bearing animals is the result of defective maturation from hemopoietic progenitors. J Immunol. 1998;161:4842-51.

168. Oyama T, Ran S, Ishida T, Nadaf S, Kerr L, Carbone DP, et al. Vascular endothelial growth factor affects dendritic cell maturation through the inhibition of nuclear factor-KB activation in hemopoietic progenitor cells. J Immunol. 1998;160:1224-32.

169. Li R, Fang F, Jiang M, Wang C, Ma J, Kang W, et al. STAT3 and NF-kB are simultaneously suppressed in dendritic cells in lung cancer. Sci Rep. 2017; 7(1):45395. https://doi.org/10.1038/srep45395.

170. Ohm JE, Shurin MR, Esche C, Lotze MT, Carbone DP, Gabrilovich DI. Effect of vascular endothelial growth factor and FLT3 ligand on dendritic cell generation in vivo. J Immunol. 1999;163:3260-8.

171. Fan X, Han B, Dong Q, Sha H, Bao G, Liao M. Vascular endothelial growth factor inhibits dendritic cells from patients with non-small cell lung carcinoma. Zhonghua Jie He He Hu Xi Za Zhi. 2003;26:539.

172. Lissoni P, Malugani F, Bonfanti A, Bucovec R, Secondino S, Brivio F, et al. Abnormally enhanced blood concentrations of vascular endothelial growth factor (VEGF) in metastatic cancer patients and their relation to circulating dendritic cells, IL-12 and endothelin-1. J Biol Regul Homeost Agents. 2001; 15(2):140-4

173. Liu Y, Luo F, Wang B, Li H, Xu Y, Liu X, et al. STAT3-regulated exosomal miR21 promotes angiogenesis and is involved in neoplastic processes of transformed human bronchial epithelial cells. Cancer Lett. 2016;370(1):12535. https://doi.org/10.1016/j.canlet.2015.10.011.

174. Baig MS, Roy A, Rajpoot S, Liu D, Savai R, Banerjee S, et al. Tumor-derived exosomes in the regulation of macrophage polarization. Inflamm Res. 2020; 69(5):435-51. https://doi.org/10.1007/s00011-020-01318-0.

175. Han Q, Zhao H, Jiang Y, Yin C, Zhang J. HCC-derived exosomes: critical player and target for cancer immune escape. Cells. 2019;8(6):558. https://doi. org/10.3390/cells8060558.

176. Ko SY, Lee W, Kenny HA, Dang LH, Ellis LM, Jonasch E, et al. Cancer-derived small extracellular vesicles promote angiogenesis by heparin-bound, bevacizumabinsensitive VEGF, independent of vesicle uptake. Commun Biol. 2019;2:1-17.

177. Shurin GV, Shurin MR, Bykovskaia S, Shogan J, Lotze MT, Barksdale EM. Neuroblastoma-derived gangliosides inhibit dendritic cell generation and function. Cancer Res. 2001;61(1):363-9.

178. Péguet-Navarro J, Sportouch M, Popa I, Berthier O, Schmitt D, Portoukalian J. Gangliosides from human melanoma tumors impair dendritic cell differentiation from monocytes and induce their apoptosis. J Immunol. 2003;170(7):3488-94. https://doi.org/10.4049/jimmunol.170.7.3488.

179. Bennaceur K, Popa I, Chapman JA, Migdal C, Péguet-Navarro J, Touraine J-L, et al. Different mechanisms are involved in apoptosis induced by melanoma gangliosides on human monocyte-derived dendritic cells. Glycobiology. 2009;19(6):576-82. https://doi.org/10.1093/glycob/cwp015. 
180. Shenoy GN, Loyall J, Berenson CS, Kelleher RJ, Iyer V, Balu-lyer SV, et al. Sialic acid-dependent inhibition of $t$ cells by exosomal ganglioside GD3 in ovarian tumor microenvironments. J Immunol. 2018;201(12):3750-8. https:// doi.org/10.4049/jimmunol.1801041.

181. S-b Y, Li Z-L, Luo D-h, B-j H, Chen Y-S, X-s Z, et al. Tumor-derived exosomes promote tumor progression and T-cell dysfunction through the regulation of enriched exosomal microRNAs in human nasopharyngeal carcinoma. Oncotarget. 2014:5:5439.

182. Lenart M, Rutkowska-Zapala M, Baj-Krzyworzeka M, Szatanek R, Węglarczyk K, Smallie T, et al. Hyaluronan carried by tumor-derived microvesicles induces IL-10 production in classical (CD14++ CD16-) monocytes via PI3K Akt/mTOR-dependent signalling pathway. Immunobiology. 2017;222(1):110. https://doi.org/10.1016/j.jmbio.2015.06.019.

183. Sharma S, Stolina M, Lin Y, Gardner B, Miller PW, Kronenberg M, et al. T cellderived IL-10 promotes lung cancer growth by suppressing both T cell and APC function. J Immunol. 1999;163:5020-8.

184. Corinti S, Albanesi C, la Sala A, Pastore S, Girolomoni G. Regulatory activity of autocrine IL-10 on dendritic cell functions. J Immunol. 2001;166(7):43128. https://doi.org/10.4049/jimmunol.166.7.4312.

\section{Publisher's Note}

Springer Nature remains neutral with regard to jurisdictional claims in published maps and institutional affiliations.

Ready to submit your research? Choose BMC and benefit from:

- fast, convenient online submission

- thorough peer review by experienced researchers in your field

- rapid publication on acceptance

- support for research data, including large and complex data types

- gold Open Access which fosters wider collaboration and increased citations

- maximum visibility for your research: over $100 \mathrm{M}$ website views per year

At BMC, research is always in progress.

Learn more biomedcentral.com/submissions 